\title{
DO TEACHER PERCEPTIONS OF SCHOOL WORKING CONTEXTS \\ CONTRIBUTE TO THE QUALITY OF TEACHER-STUDENT INTERACTIONS IN THE CLASSROOM?
}

\author{
A Dissertation \\ Presented to the Faculty of the Curry School of Education \\ University of Virginia
}

In Partial Fulfillment of the Requirements for the Degree

Doctor of Philosophy

by

Carol L.C. Paxton, MEd

August 2016 
(C) Copyright by Carol L. C. Paxton All Rights Reserved August 2016 


\begin{abstract}
Advisor: Sara Rimm-Kaufman

The purpose of this study was to: (a) examine the underlying factor structure for collective teacher efficacy, (b) describe individual teacher perceptions of collective efficacy, as well as correlation patterns with classroom observation scores, and (c) analyze the strength of association between the collective efficacy perceptions of 392 fourth- and fifth-grade teachers and their scored observed interactions with students in the classroom. This study is the first to examine individual teacher perceptions of collective efficacy as a member of a teaching team and their observed performance in the classroom. Three stages of analyses were conducted to obtain results.

First, a collective teacher efficacy measure was constructed based on the original Collective Teacher Efficacy Scale by Goddard, Hoy, and Woolfolk Hoy (2000). This process involved reducing items from the Teacher Working Conditions survey from the Measures of Effective Teaching Project and employing exploratory factor analysis. Confirmatory factor analysis revealed a two-factor structure for the nine items selected for the measure used in the present study. Characteristics of the two factors were consistent with definitions for the group competence and task analysis constructs of Goddard and colleagues' (2000) collective teacher efficacy theory. Task analysis and group competence correlated at $r=.406(p<.01$, two-tailed $)$.

Second, descriptive statistics indicated that teachers agreed with group competence statements $(M=2.36, S D=.59)$ more often than task analysis statements $(M$ $=3.23, S D=.49)$. There was also less variability around the mean for group competence than for task analysis. Third, bivariate correlations between collective efficacy constructs
\end{abstract}


and CLASS observation dimension scores were weak $(r \leq .20)$. However, significant associations foreshadowed the results of structural equation model. Results from the structural equation models showed that group competence significantly correlated with teachers' emotional support toward students in the classroom $(\beta=.29, p<.05)$.

Findings from the study will support future work. The two-factor structure has implications for the development of alternative measures of collective efficacy and the conceptualization of collective efficacy in other research studies. Further investigations of teacher collective efficacy perceptions and the relationship that group competence shares with emotional support provided in the classroom have distal implications for the actions of policymakers, program developers, and administrators seeking additional strategies for school improvement.

Keywords: teacher efficacy, collective efficacy, teacher perceptions, teacher working conditions, teacher student interactions 


\title{
Educational Psychology: Applied Developmental Science Curry School of Education \\ University of Virginia \\ Charlottesville, Virginia
}

\begin{abstract}
APPROVAL OF THE DISSERTATION
This dissertation, ("Do Teacher Perceptions of School Working Contexts Contribute to the Quality of Teacher-Student Interactions in the Classroom?"), has been approved by the Graduate Faculty of the Curry School of Education in partial fulfillment of the requirements for the degree of Doctor of Philosophy.
\end{abstract}

Dr. Sara Rimm-Kaufman, Chair

Dr. Nancy Deutsch, Committee Member

Dr. Pamela Tucker, Committee Member

Dr. Jamie De Coster, Committee Member 


\section{DEDICATION}

For Ben and Pagan, the family we have made together - I love you more than I can say. My eternal thanks for helping me through this process.

For Ma, Edward, Daddy, Heather, the nephews, the Evans clan, the clans of the Clarks, and my new family - the Paxtons and Sands - thank you for your love, encouragement, and support.

And for Scott, Becky, Dirk, Sandra, Tabatha, Cindy Ann and Moe, Chris, Manuela, Sara O’ and the other friends who have become family, too - through our conversations, shared laughter, and trials together, you have all made me a better person. I look forward to future adventures in the years to come. 


\section{ACKNOWLEDGEMENTS}

There are a number of individuals I would like to thank for their contributions to my education and training as I pursued my doctoral degree.

I would like to thank my advisor, Sara Rimm-Kaufman, for the opportunity to learn from her. I have been very lucky.

I would also like to thank my dissertation committee: Nancy Deutsch, Pamela Tucker, and Jamie DeCoster. I will always be grateful for your patience, feedback, and support throughout this process.

My appreciation extends to the faculty at Curry, as well, who have taught me so much through their example.

Additional appreciation goes to Julie Thomas and Michelle Ko. You always made the Social Development Lab feel like home. My gratitude also extends to our postdoctoral scholars who have shared their guidance along the way. Thank you, Shannon Wanless, Christine Patton, Lia Sandilos, and Ross Larsen.

In addition, I could not have completed this journey without the support and friendship of Tashia Abry, Micela Leis, and my other fellow graduate students. I hope our conversations and camaraderie enriched your time at the University of Virginia as much as it did mine.

And finally - Thank you, Diane Whaley, who advocated for my admission into the Educational Psychology: Applied Developmental Science program, always offered encouragement, and believed in me. I am grateful. 


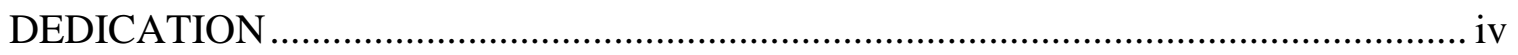

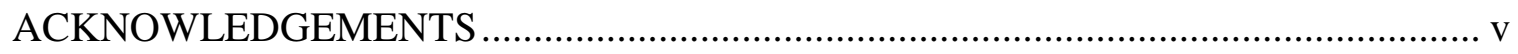

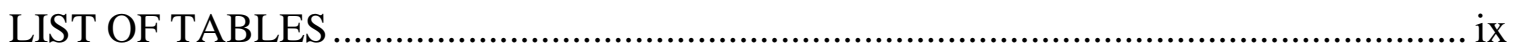

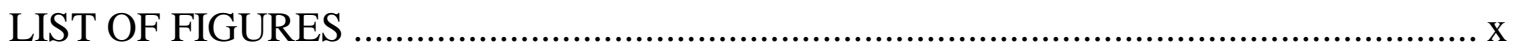

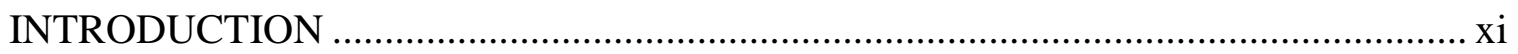

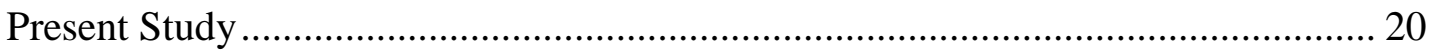

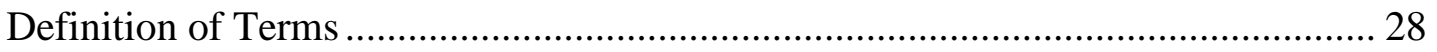

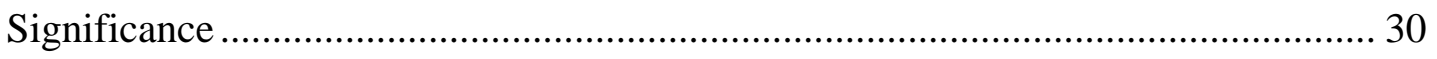

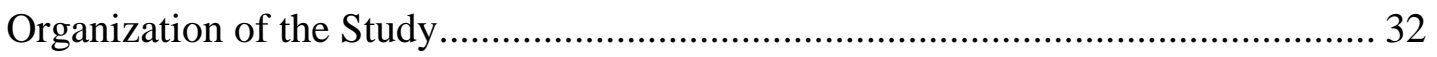

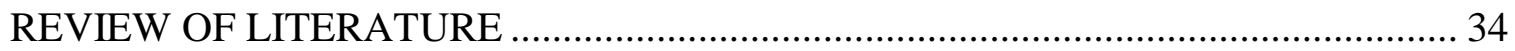

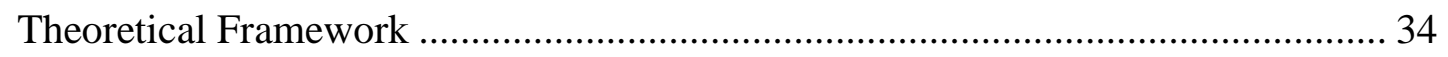

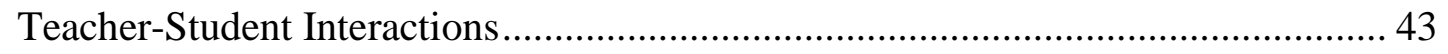

The Intersection of Study Constructs ........................................................ 50

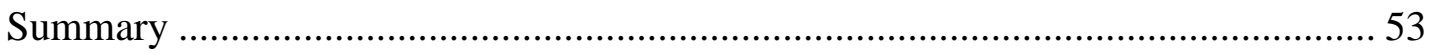

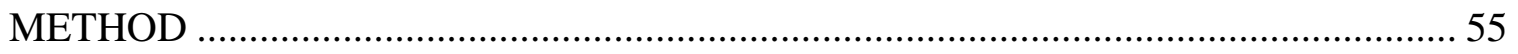

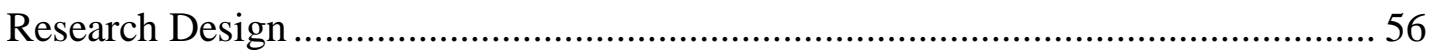

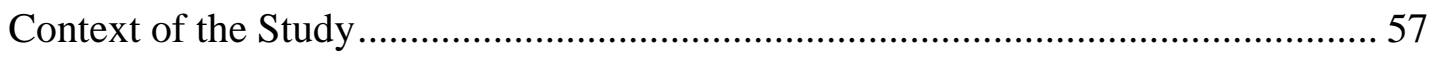




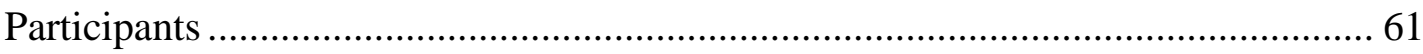

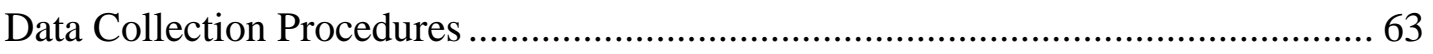

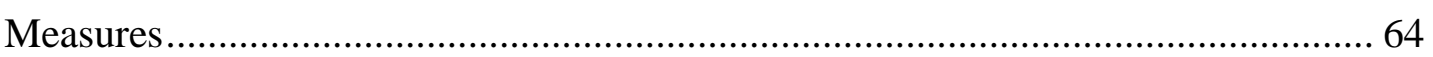

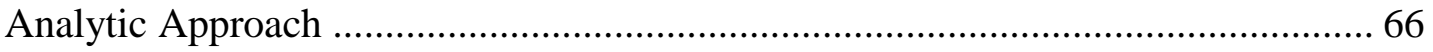

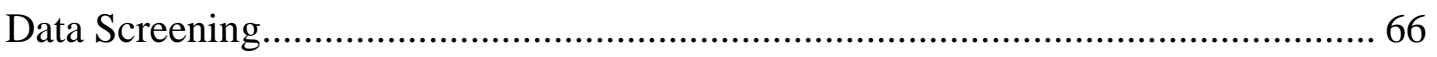

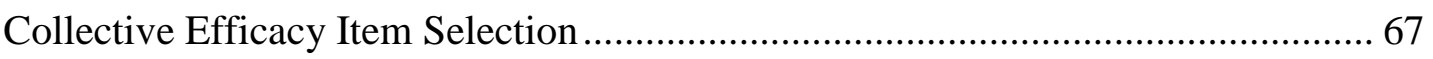

Exploratory Factor Analyses ............................................................................... 68

Confirmatory Factor Analysis ................................................................................ 71

Descriptive Analysis......................................................................................... 71

Structural Equation Modeling ……………………………………..................... 72

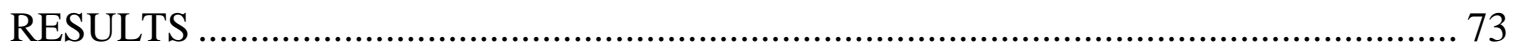

Exploratory Factor Analysis ................................................................................ 73

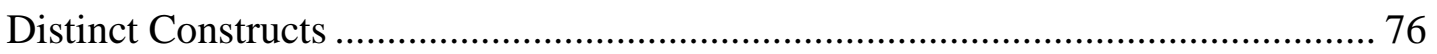

Description of Collective Efficacy Perceptions ……………...................................... 77

Collective Efficacy and Teacher-Student Interactions ............................................ 80

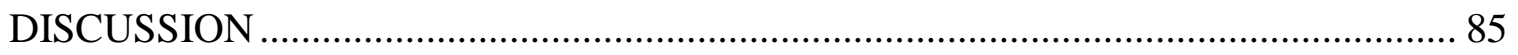

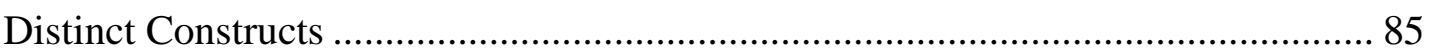

Description of Collective Efficacy Perceptions …………....................................... 89

Collective Efficacy and Teacher-Student Interactions ............................................. 95

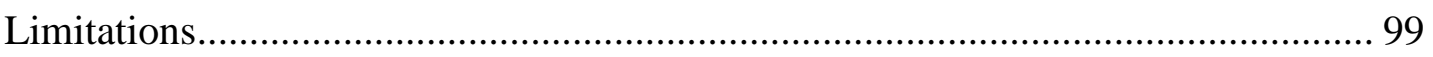

Contributions and Future Research ....................................................................... 101

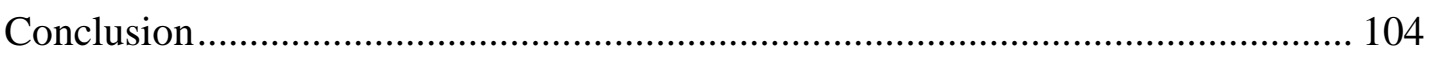

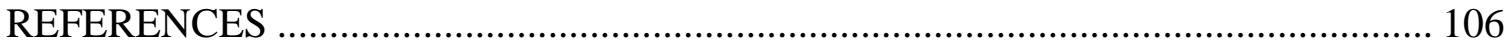




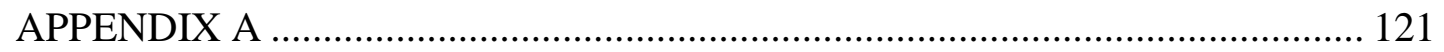

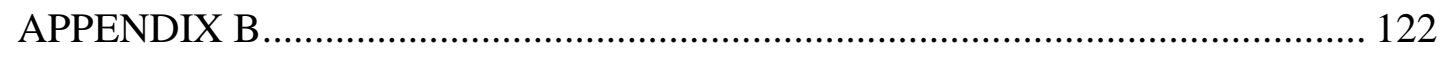

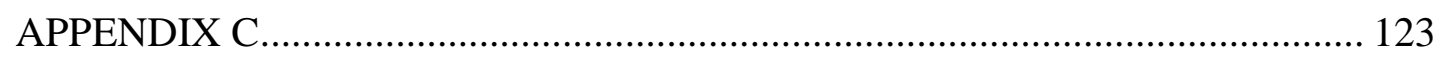




\section{LIST OF TABLES}

Table 1.1: Descriptive Characteristics of the Sample

Table 2.1: Frequency of Teachers in the Sample With the Following Classroom

Characteristics

Table 3.1: Exploratory and Confirmatory Factor Analysis Models

Table 4.1: Retained Teacher Working Conditions Survey Items and Standardized Factor

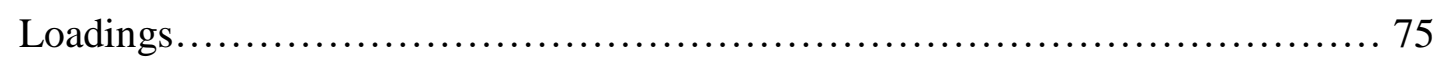

Table 5.1: Correlations and Descriptive Statistics for Collective Efficacy Constructs,

CLASS Dimensions, and Domains

Table 5.2: Correlations and Descriptive Statistics for Collective Efficacy Constructs, CLASS Dimensions, and Domains (Continued) 79

Table 6.1: Standardized Parameter Estimates Path Coefficients and Fit Indices for Structural Model 83 


\section{LIST OF FIGURES}

Figure 1. Theoretical model of perceived collective efficacy in schools, adapted from

Goddard, Hoy, and Woolfolk Hoy (2000)............................................................ 16

Figure 2. Hypothesized model for confirmatory factor analysis corresponding to $H 1 b$. . 23

Figure 3. Hypothesized one-factor conceptual model of collective efficacy with direct effects on each observed domain of teacher-student interactions in the classroom,

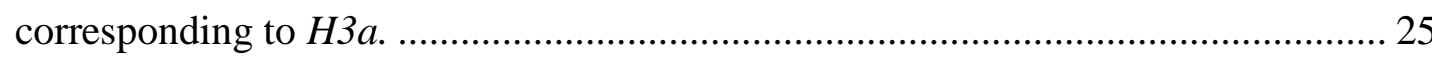

Figure 4. Hypothesized two-factor conceptual mediation model with indirect effects on each observed domain of classroom instruction, corresponding to $H 3 b$................... 26

Figure 5. Hypothesized ( $\mathrm{H} 3 a$ ) structural regression path model showing the direct effects of collective efficacy on each of the three CLASS domains.......................................5 58

Figure 6. Hypothesized $(H 3 b)$ structural regression path model with task analysis mediating the effect of group competence on each of the three CLASS domains .... 59

Figure 7. Confirmatory factor analysis loadings for the task analysis and group competence factors of collective efficacy theory 77

Figure 8. Final model with group competence (GC) directly affecting task analysis (TA) and the emotional support (ES) domain of teacher-student interaction quality 82 


\section{CHAPTER ONE}

\section{INTRODUCTION}

High-quality teaching stands as the most important school-based mechanism for improving student outcomes (Coleman et al., 1966; Goldhaber, 2002; Nye, Konstantopoulos, \& Hedges, 2004). Findings from studies investigating teacher effects on student achievement in the 1970s (e.g., Anderson, Everston, \& Brophy, 1979; Good \& Grouws, 1977) revealed the strong influence teachers have on academic performance by identifying teaching procedures associated with achievement test gains. The identification of effective teaching processes informed the later development of formal classroom teacher observation measures used in additional studies confirming that high-quality classroom instruction leads to positive academic outcomes (Kane, Kerr, \& Pianta, 2014; Kane \& Staiger, 2012; Rockoff \& Speroni, 2010).

High-quality instruction begins with careful preparation and detailed planning; the classroom teacher establishes an inviting environment for the pursuit of learning by providing the necessary tools for individual and group problem-solving as students interact with their surroundings. Routines and norms in the classroom create organized structures for safe interactions among students, as well as between the teacher and student. The teacher initiates and guides analytical inquiry while modeling ways for students to find answers. At the same time, social and emotional growth develops as the teacher listens intently to student joys and compassionately shows regard for student concerns and expressed needs. 
When student-initiated conversation is also valued just as highly as teacher-driven discourse, positive outcomes rise from opportunities for students to engage with their environments, react to their environments, and reflect upon their experiences. Students who pursue goals with positive expectations come to develop an ever-evolving understanding of themselves and their capabilities. The teacher sustains student motivation through mistakes by providing encouragement with quality feedback, engaging in deeper instructional dialogue, and lighting the path for students to return to a puposeful course of action. The importance of the teacher and their capacity to create positive student outcomes is easily understood when one considers the impressive task of creating and guiding this miniature world,

As illustrated, the classroom exists as an interactive ecological system for student development; similarly, the school context facilitates (or constrains) teacher development. Professional contexts strongly influence teacher psychology, the perceptions of teachers, teacher learning, and resulting behavior. Understandably, the importance of teachers makes it critical for students to be taught by psychologicallyhealthy individuals using high-quality teaching practices (Rimm-Kaufman \& Hamre, 2010). Attention to the ways in which teachers perceive their working contexts and the effectiveness of their colleagues informs how those psychological influences may shape individual teaching practices. After a multitude of studies examining the high-quality instructional practices of teachers in isolated classrooms, researchers can now build upon this foundation by investigating the influence that individual teacher perceptions of obstacles and supports in school working contexts have on interactions with students. Teachers operate with their colleagues as part of a team. Whether the perceptions of the 
obstacles and supports faced by the team influence individual teacher behaviors in the classroom has yet to be explored. Evidence of this association has the valuable potential to develop new innovations and untried avenues to school improvement.

The process of becoming a high-quality teacher is ongoing and complex. Teachers' choice of behavior depends upon the way they reflect upon their experiences, form perceptions, and receive guidance to make instructional decisions in the classroom. Both formal and informal professional experiences shape teacher development. Participating in formal professional development opportunities, such as workshops, lectures, and trainings, can influence individual teaching quality. However, attending a seminar is only one step in the process of teacher learning and improvement.

The formal process of professional development is typically accompanied by an informal experience, as well. For instance, most teachers receiving professional development reflect upon learning experiences through informal conversations with colleagues at their school. As a grade-level group, teachers may attend a professional development seminar in the morning. Later, during an informal lunch conversation together in the teachers' lounge, they will weigh the value of the seminar's lessons. In turn, this will influence individual decisions about implementing the seminar's content in their own classrooms in the future. However, in the course of providing professional learning opportunities, school divisions and administrators typically prioritize the formal learning experience. At the same time, they fail to consider the informal social and environmental factors that spur teacher reflection, shape the formation of teacher perceptions, and influence the psychological processes that determine whether teachers will choose to adopt new approaches to teaching or discard the latest initiative. 
Researchers, administrators, and policymakers have given some attention to the importance of providing positive professional contexts for teachers. Prior education policy research suggests that improving teacher perceptions of working conditions will result in effective instruction and beneficial student outcomes (Johnson, Kraft, \& Papay, 2012; Kraft \& Papay, 2014; Ladd, 2011). However, these studies are concerned with the compensation, benefits, and resources provided to teachers.

Psychological studies of teacher efficacy have shown associations between student outcomes and individual perceptions of supports and obstacles in school working contexts (e.g. Tschannen-Moran, Woolfolk Hoy, \& Hoy, 1998; Tschannen-Moran \& Barr, 2004), although none of these investigations have explored whether perceptions of individuals as part of a teaching team affect the quality of teacher-student interactions in the classroom. Within the purview of these studies, collective efficacy (also termed collective teacher efficacy) stands out as an important social construct for understanding teachers' perceptions of working conditions (Goddard, 2002; Goddard, Hoy, \& Woolfolk Hoy, 2000; Goddard, Hoy, \& Woolfolk Hoy, 2004). To help illustrate its importance, Figure 1 provides an overview of collective efficacy theory. We see how collective efficacy is comprised of two subconstructs: group competence and task analysis. Group competence refers to the perception of a school's teaching staff regarding how the combined abilities of its group members influence positive student outcomes. Task analysis refers to the estimation of a teaching task's difficulty, as well as the perceived supports or challenges to teaching that will affect student outcomes. Positive collective efficacy perceptions held by groups of teachers are associated with high student academic performance (Goddard, Hoy, \& Woolfolk Hoy, 2000; 2004). 
As previously stated, observed high-quality classroom practices are also associated with positive academic outcomes (Kane, Kerr, \& Pianta, 2014; Kane \& Staiger, 2012; Rockoff \& Speroni, 2010). However, the strength of association between individual teacher perceptions of collective efficacy as part of a school's teaching team and the high-quality instructional behaviors of those individuals in classrooms remains unexplored. To date, there is little to no understanding of how an individual teacher's feeling of team effectiveness, as well as perceived obstacles or supports in the work environment, relate to the teacher's day-to-day interactions with his or her students in the classroom. 


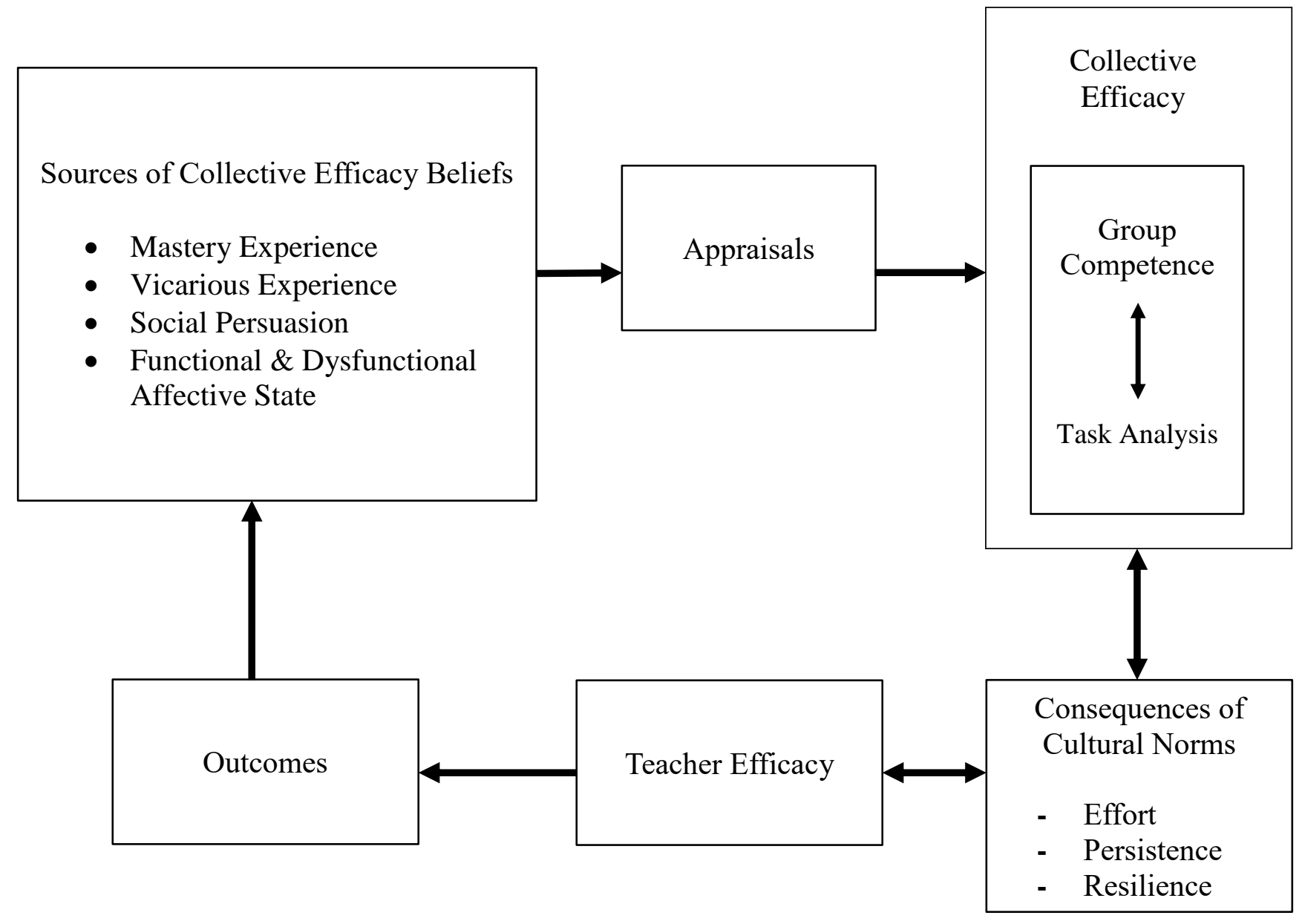

Figure 1. Theoretical model of perceived collective efficacy in schools, adapted from Goddard, Hoy, and Woolfolk Hoy (2000). 


\section{Statement of the Problem}

The working life of a teacher is an intensely social experience. Teachers and administrators constantly engage in both formal and informal professional interactions with each other. Federal and state mandates increasingly require teachers to emerge from the isolation of their classrooms and work together in a variety of capacities to improve student outcomes (Hargreaves \& Fullan, 2012; Goddard, Goddard, \& Tschannen-Moran, 2007; Odden, 2011). As a result, the professional interactions that teachers have in their school environments may be more important than ever before. For example, education professionals now collaborate throughout the process of implementing programs (Domitrovich et al., 2008), in child study meetings (Burns \& Symington, 2002; Moore, Fifield, Spira, \& Scarlato, 1989), on school improvement committees (Smylie, Conley, \& Marks, 2002), in professional learning communities (DuFour, 2004), and during common lesson planning (e.g., Perry \& Lewis, 2008). Participation in these activities can provide new perspectives and a clearer understanding of the supports and obstacles the teaching staff encounter in their task of educating students. These interactions can also take on positive qualities that lead to shared accomplishments and shared values. Alternatively, they may also lead to demoralizing disagreements, in-fighting, and a lack of focus.

In collective efficacy theory, teacher perceptions of their professional interactions and experiences are key; supporting the development of positive teacher perceptions of colleagues and professional contexts improves the psychological well-being of the group and, as a result, presumably fosters high-quality instruction in classrooms (Goddard, 2002; Goddard, Hoy, \& Woolfolk Hoy, 2000; Goddard, Hoy, \& Woolfolk Hoy, 2004). Collective efficacy theory holds that collaborative problem solving and decision making 
are most effective when teachers and principals in a school share the perception that group efforts will result in positive student outcomes. Both teachers and students are likely to benefit.

Previous studies have established the association between collective efficacy perceptions and student standardized test scores (Bandura, 1993; Goddard, Hoy, \& Woolfolk Hoy, 2000; 2004). Theorists also emphasize the importance of acknowledging collective efficacy as an influential, self-perpetuating construct (Bandura, 1997; Goddard, Hoy, \& Woolfolk Hoy, 2000; 2004; Tschannen-Moran \& Barr, 2004). When positive collective efficacy perceptions are high, these perceptions are associated with additional positive perceptions and outcomes among group members. Negative collective efficacy perceptions are associated with a downward spiral of additional negative perceptions and undesirable outcomes. This compels us to further understand the nature of collective efficacy and the way in which it contributes to day-to-day behavior in the classroom. New knowledge in this area will support efforts to guide the potential for collective efficacy to influence positive outcomes.

One step in accomplishing this is to explore the more proximal potential association between individual teacher perceptions of collective efficacy and high-quality teaching. This is the "black box" that exists between teacher perceptions of collective efficacy and student outcomes. We lack an understanding of whether and how highquality teaching behaves as a bridge between collective efficacy perceptions and positive student outcomes. However, for the first time we have data from the Gates Foundation Measures of Effective Teaching (MET) Project data set (Bill \& Melinda Gates Foundation, 2010), a large national data set with information about teachers' perceptions 
of many different aspects of their working contexts, as well as each individual teacher's composite scores based on classroom observations over the course of a year. With this body of data, we have a valuable opportunity to learn more about the nature of the constructs present within collective efficacy theory and instructional practices associated with the perceptions of individual teachers who are conscious of their roles as part of a teaching team.

Individuals associated with academic and research institutions assisting with the project published the first wave of studies using the MET data (see Kane, Kerr, \& Pianta, 2014). Although several researchers have conducted investigations with MET data to answer many questions, only one study analyzed data from the Teacher Working Conditions (TWC) survey administered in the spring of 2010 (Ferguson \& Hirsch, 2014). The co-author of the study, Eric Hirsch, is Chief External Affairs Officer for the New Teacher Center, the institution which provided an adapted version of the TWC for the MET Project. The New Teacher Center (NTC) has for many years administered the survey to teachers in thousands of school divisions across the country for many years as part of NTC consulting services. The TWC survey was originally used in policy studies investigating how teacher working conditions predict teacher mobility (Ladd, 2009; 2011), as well as student outcomes (Ladd, 2009). The current version of the MET TWC survey is divided into nine scales with 232 items querying use of teacher time, facilities and resources, community support and involvement, school characteristics, student conduct, leadership, instructional practice and support, and professional development. These scales include items that resemble or were from the Collective Teacher Efficacy Scale (see Appendix A) (Goddard, Hoy, \& Woolfok Hoy, 2000). In other words, teacher 
responses to the MET TWC survey offer a rich source of data required for understanding how constructs measured in the survey relate in important ways to high-quality teaching.

In the present study, I operationalize high-quality teaching as successful instruction through teacher-student interactions, as measured by the Classroom Assessment Scoring System [CLASS] (Pianta, Hamre, \& Mintz, 2012) used in the MET Project study. Teachers interact effectively with their students by showing responsiveness to student behaviors and interests, establishing clear routines and objectives, and providing instruction that is meaningful while fostering critical thinking through conversation and feedback. I am exploring the related questions: Do teacher perceptions of school working contexts relate to teacher performance in the classroom? More specifically, are individual teacher perceptions of collective efficacy associated with the quality of observed teacher interactions with students?

As a first critical step in examining the strength of the relation between collective efficacy perceptions and teacher-student interactions, the framework for collective efficacy theory requires additional confirmation and consolidation. A recent paper by McCoach and Colbert (2010) questions the underlying tenets of collective efficacy theory by proposing a factor structure that differs from the most commonly used approach. Before we can investigate the relation between individual teacher perceptions of collective efficacy and classroom interactions, we must test collective efficacy theory and its hypothesized subconstructs of group competence and task analysis more thoroughly.

\section{Present Study}

The present study has multiple aims to achieve one overarching goal. The overarching goal is to examine the extent to which individual teacher perceptions of 
collective efficacy relate to the quality of teacher-student interactions in fourth- and fifthgrade classrooms. The first aim is to confirm the collective efficacy construct as consisting of two distinct factors that describe teachers' perceptions of their working context. The second aim is to use these factors to describe average levels and ranges of teachers' perceptions of collective efficacy in a large national sample of teachers. The third aim is to model hypothesized relational paths between collective efficacy and the quality of teacher-student interactions, then test the extent to which factors associated with collective efficacy relate to teacher-student interaction quality in the classroom. To pursue these aims, I propose using the MET Project data set (Bill \& Melinda Gates Foundation, 2010) to answer the three research questions and hypotheses below:

Aim 1, Confirmatory Factor Analysis: Research Question 1 (RQ1):

What are the underlying factor structures for collective efficacy that emerge from a broad survey of fourth- and fifth-grade teacher perceptions of school working contexts?

Hypothesis la (HIa):

Collective efficacy will emerge as a single factor without differentiation between the elements of group competence and task analysis.

OR,

Hypothesis $1 b(H 1 b)$ :

Constructs associated with collective efficacy (group competence and task analysis) will manifest as latent variables for inclusion in a two-factor model.

Figure 2 illustrates the hypothesized confirmatory factor analysis (CFA) model for H1b. Two proposed factor structures exist for collective efficacy theory. Goddard, 
Hoy, and Woolfolk Hoy (2000) originally found a one-factor model during piloting of the long form of the Collective Efficacy Scale. The authors maintained that the correlation between the emerging factors of group competence and task analysis $(r=.75, p<.001)$ suggested a model fit uniting the two as interrelated theoretical constructs comprising collective efficacy in a one-factor solution. However, McCoach and Colbert (2010) challenged this decision and advanced a two-factor solution that separated group competence and task analysis as individual constructs.

Aim 2, Descriptive Characteristics: Research Question 2 (RQ2):

What are the descriptive characteristics of fourth- and fifth-grade teachers' perceptions of collective efficacy?

Hypothesis 2 (H2):

The wide variety of characteristics in working contexts encountered by teachers from 105 schools across five school divisions in the sample will contribute to an equally wide range of teacher perceptions of collective efficacy.

Aim 3, Structural Equation Modeling: Research Question 3 (RQ3):

To what extent do teachers' collective efficacy perceptions relate to observed levels of teacher-student interaction quality in the classroom (i.e., emotional support, classroom organization, and instructional support)? 


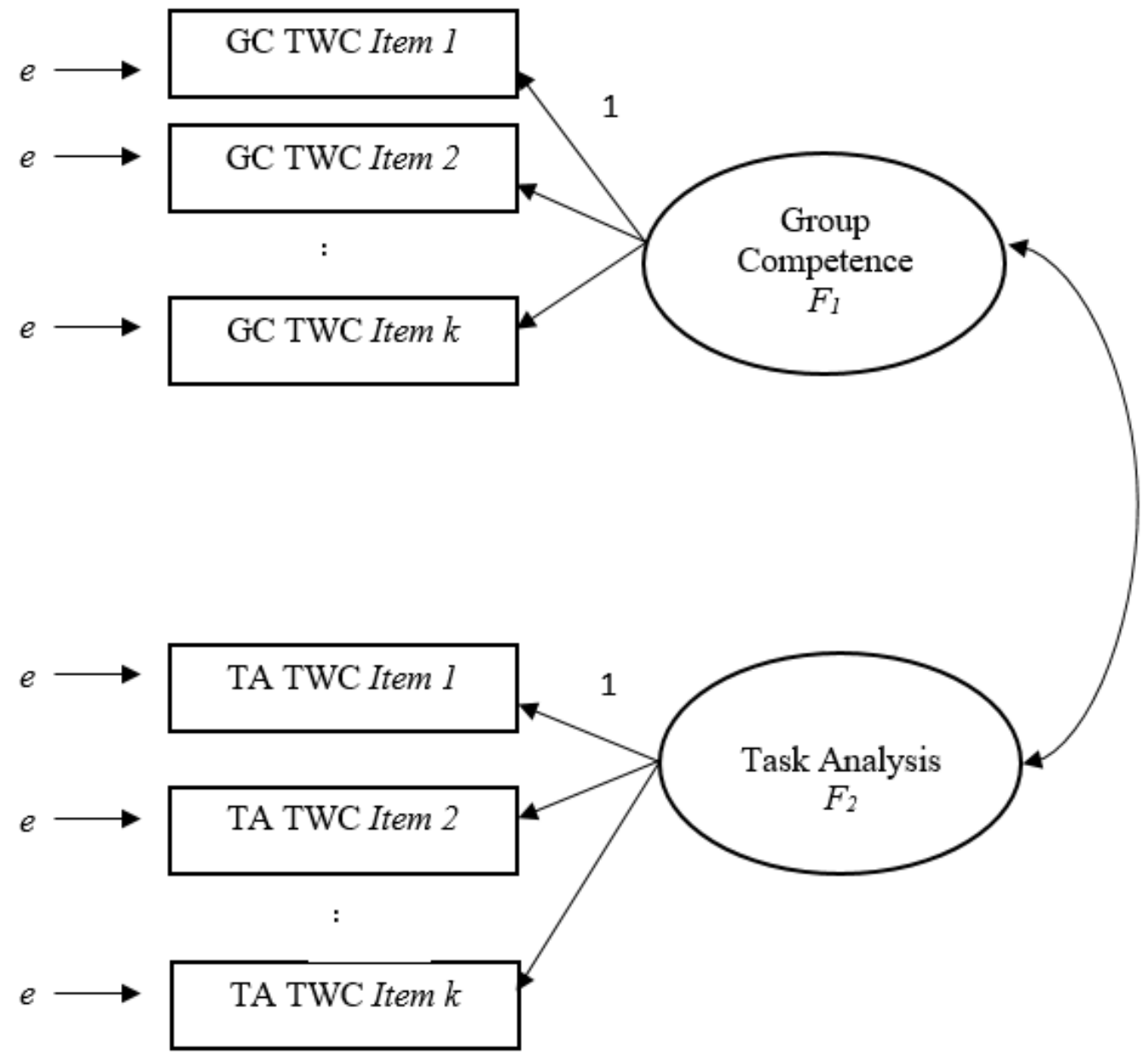

Figure 2. Hypothesized model for confirmatory factor analysis corresponding to $H 1 b$. 
Hypothesis $3 a(H 3 a)$ :

If collective efficacy is confirmed as a one-factor model, collective efficacy will have a direct effect on each of the three domains of teaching (e.g., emotional support, classroom organization, and instructional support). A significantly stronger association will exist between collective efficacy and the emotional support and instructional support domains compared to the classroom organization domain.

OR,

Hypothesis $3 b(H 3 b)$ :

If collective efficacy is best represented as a two-factor model, a mediation model will be the best fit for explaining how group competence and task analysis relate to observed levels of teacher-student interaction quality in the classroom. Perceptions of task analysis will mediate the relation between group competence and teacher-student interaction quality. Further, I expect this mediated effect will be stronger for the effects of group competence on the emotional support and instructional support domains of instruction than for classroom organization.

Figure 3 and Figure 4 illustrate the hypothesized conceptual models for $\mathrm{H} 3 \mathrm{a}$ and $\mathrm{H} 3 \mathrm{~b}$, respectively. Previous findings from an exploratory mixed methods study of collective efficacy in schools generated new theories that lead to the hypothesized associations and presence of mediation in the model (Paxton, Leis, \& Rimm-Kaufman, 2015). To illustrate, when teachers reported consistent efforts by fellow staff members to improve collegiality in support of one another, teachers also recounted mirroring personal 


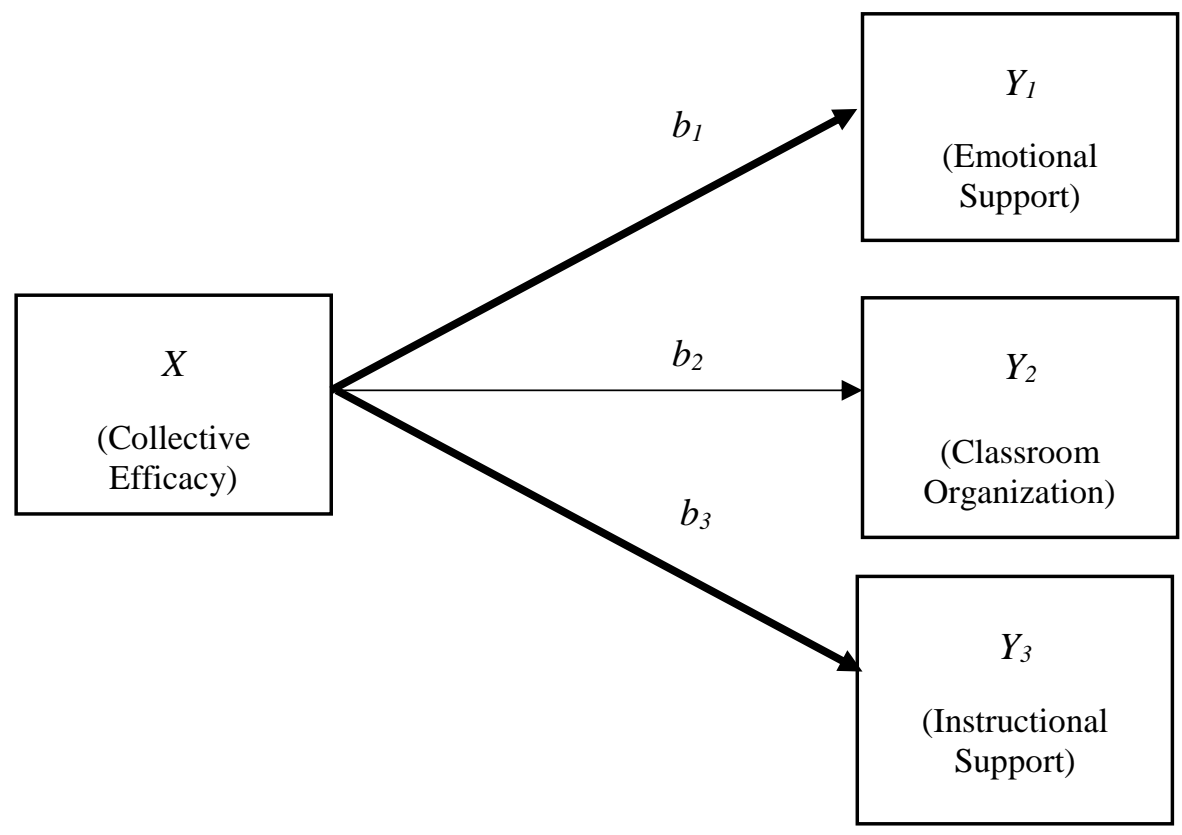

Figure 3. Hypothesized one-factor conceptual model of collective efficacy with direct effects on each observed domain of teacher-student interactions in the classroom, corresponding to $H 3 a$. 


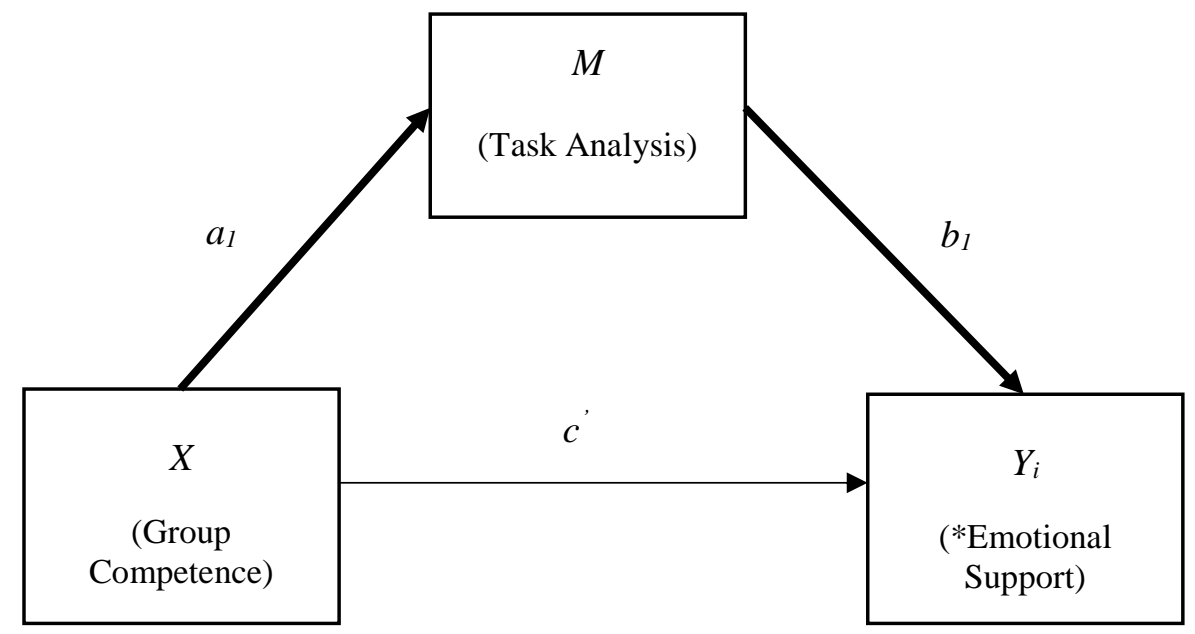

Figure 4. Hypothesized two-factor conceptual mediation model with indirect effects on each observed domain of classroom instruction, corresponding to $H 3 b$.

*Note: Emotional support is interchangeable with the other two observed domains of classroom instruction: Classroom Organization and Instructional Support. 
efforts to improve relationships among their own classroom communities. Thus, the qualitative data suggested that positive perceptions of group competence were associated with teacher efforts to improve emotional support in the classroom. It would also follow that teachers with a positive sense of well-being, enhanced by working in a psychologically-healthy school context, would provide effective emotional support to students.

In the Paxton and colleagues (2015) study, teachers who experienced greater group competence said they were more likely to initiate collaboration with a wider pool of colleagues. This would increase the likelihood of teachers collaborating with one another on their own. Schools in which teachers engage in frequent collaborative efforts have been shown to have higher levels of academic achievement when compared with schools with fewer instances of collaboration among teachers (Goddard, Goddard, \& Tschannen-Moran, 2007). Therefore, knowing that high-quality instruction is associated with higher levels of academic achievement, I hypothesize that positive levels of collective efficacy will also correlate significantly with more effective instructional support in classrooms.

Notice that both rationales for hypothesized strong associations between collective efficacy and emotional support, as well as collective efficacy and instructional support, are contingent upon teacher perceptions of group competence. Another finding from the Paxton et al. study leads to the hypothesis that task analysis mediates the relationship between group competence and teacher efforts to support students. Many teachers in the study held positive perceptions of their colleagues and showed high group competence. However, teachers felt that significant obstacles in their working 
environments made it difficult for the group of teachers at their schools to support positive student outcomes. Among the perceived obstacles listed were a lack of time, a lack of support from parents, and frequent testing on learning standards deemed inappropriate for subjects taught. This is an example supporting the mediation hypothesis; the positive relationship between perceived group competence and highquality instruction in the classroom may be mediated by task analysis.

\section{Definition of Terms}

Key study constructs are defined below. They include teacher working contexts (Bill \& Melinda Gates Foundation, 2010), collective efficacy, group competence, and task analysis (Goddard, Hoy, \& Woolfolk Hoy, 2000; 2004). I also define terms associated with teacher-student interactions and instructional quality, including emotional support, classroom organization, and instructional support (Pianta, Hamre, \& Mintz, 2012). In depth explanations of these terms and their theoretical foundations are located in the literature review portion of the next chapter.

The following terms are used throughout this study:

I. Teacher perceptions of working contexts: Teachers' assessments of the quality of components associated with their workplace, such as community engagement and support, instructional practices and supports, professional development, school and teacher leadership, student conduct, time, and facilities and resources (Bill \& Melinda Gates Foundation, 2010; Ferguson \& Hirsch, 2014).

A. Collective efficacy: The perception that group efforts by teachers in a school will result in positive student achievement outcomes (Bandura, 1993; 1997; Goddard, Hoy, \& Woolfolk Hoy, 2000; 2001). 
1. Group competence: One of two subconstructs comprising collective efficacy. Group competence is the estimation of the collective educational staff's inherent capability to improve student achievement outcomes (Goddard, Hoy, \& Woolfolk Hoy, 2000; 2001).

2. Task analysis: One of two subconstructs comprising collective efficacy. Task analysis is the estimation of the feasibility of successfully teaching, as well as how factors external to the task of teaching provide support or create obstacles for collective staff efforts to improve student achievement outcomes (Goddard, Hoy, \& Woolfolk Hoy, 2000; 2001).

II. Instructional quality: The degree to which teachers are able to support student outcomes through their interactions with students (Hamre et al., 2013; Pianta, Hamre, \& Mintz, 2012). Most teacher-student classroom interactions can be categorized within the three domains described below.

A. Emotional support: Emotional support refers to the approaches teachers use during interactions intended to facilitate student social and emotional growth. Teachers high in emotional support consciously include student perspectives in activities, honor individual student differences, and interact in ways that are responsive to the needs of students (Pianta, Hamre, \& Mintz, 2012). In classrooms high in emotional support, students take risks while seeking support from their teacher, are encouraged to exercise autonomy and leadership, and engage in productive, positive peer interactions under the guidance of the instructor.

B. Classroom organization: Classroom organization refers to the ability of the teacher to manage student time, attention, and behavior throughout the day 
(Pianta, Hamre, \& Mintz, 2012). Teachers with strong classroom organization skills are proficient in behavior management and foster high levels of student productivity. In classrooms with high classroom organization, students appear productively engaged in instructional activities, seem to understand clear expectations for their tasks and behavior, and are offered a variety of interesting classroom materials and learning formats to expand their knowledge.

C. Instructional support: Teachers providing strong instructional support foster student cognitive and language development to encourage learning while providing both key ideas and the broad framework of content areas (Pianta, Hamre, \& Mintz, 2012). This includes purposefully facilitating conversations that promote higher-level thinking skills and extending student responses by providing constructive feedback. In classrooms with high instructional support, students receive scaffolding and affirmations to guide conversations that help students practice problem solving and reflective analysis rooted in real-world situations.

\section{Significance}

This study contributes to the work of researchers, policymakers, and administrators in many ways. For researchers, I address the question of the factoral structure for the collective efficacy construct. To accurately study and effectively apply collective efficacy theory in teaching contexts, researchers will benefit from this investigation of whether group competence and task analysis are distinct constructs and how these constructs may work together. As a proximal accomplishment, this work lays the foundation for future studies. 
Also, the Teacher Working Conditions Survey in the current study is a close adaptation of a similar measure used to provide information to many school divisions nationwide. In 1997, Pajares reasoned that although the investigation of collective efficacy as a construct is critical for schools, few studies of collective efficacy have been conducted due to the onerous task of undertaking sufficient data collection. The breadth of data collected for the recent MET project creates an opportunity to test collective efficacy theory and explore potential correlations between teacher perceptions of school environments and teacher behaviors in the classroom. One value of this study lies in its exploratory nature as theories of collective efficacy are tested. This study also explores the potential for select items in the survey to be used for an updated, modern assessment of collective efficacy in schools. After further testing of validity and reliability, an assessment of collective efficacy perceptions embedded in the full survey could provide valuable information about teachers' psychological states and the perceived potential of colleagues in schools.

According to collective efficacy theory, collective efficacy is a pre-existing, dynamic construct; policymakers and administrators would benefit from knowing whether, and how, individual teacher perceptions of collective efficacy are producing cycles of positive or negative teaching behaviors in school classrooms. Task analysis refers to the estimation of task difficulty and the obstacles or supports to accomplishing goals. Sometimes these obstacles and supports are created by the legislative and budgetary decisions of policymakers. Understanding the psychological impact of policy decisions on the collective efficacy of teachers could influence legislative and budgetary outcomes. 
Similarly, administrators will benefit from understanding the value of supporting teachers and the liabilities of ignoring obstacles in teacher working contexts at the local level. This work may contribute to administrators having a better understanding about the importance of facilitating a positive sense of group competence on staff. Supporting staff resilience as a group facing obstacles and creating support structures for individual members of teams of teachers may translate into improved teacher-student interactions in the classroom. The design of the present study is unique as it considers individual teacher perceptions of collective efficacy and examines the quality of interactions between the individual teachers and their students. Previous studies of collective efficacy have examined the unified perception of groups of teachers, not the perceptions of individual teachers who are conscious of their membership as part of the group. In examining data at the individual teacher level, it is possible to explore the relation between an individual teacher's perceptions as a member of a group and their individual observation scores for classroom interactions with students. Thus, the present study may contribute evidence that teacher perceptions of group competence, as well as individual perceptions of supports and obstacles mediating the effects of group competence, are associated with the quality of teacher-student interactions in the classroom.

\section{Organization of the Study}

In the current chapter, I establish the need to conduct an empirical investigation on the contribution of teachers' perceptions of collective efficacy to teacher-student interactions in the classroom. I propose conducting factor analyses and latent variable path modeling to test collective efficacy theory using survey and observational data from fourth- and fifth-grade teachers participating in the MET Project. I introduce terms to be 
used throughout the remainder of this document. I will expand upon and explain these terms in the context of a literature review in the next chapter, Chapter 2. Chapter 3 describes the methods proposed for investigating the three introduced research aims. The remaining chapters, Chapters 4 and 5, will report the results of analyses and conclude with a discussion of importance and implications, respectively. 


\section{CHAPTER TWO}

\section{REVIEW OF LITERATURE}

This chapter establishes the theoretical frameworks underlying the present study and provides detailed explanations for terminology used throughout this work. I also describe previous studies informing the research hypotheses under investigation. The content presented provides background information for understanding this study's investigation of collective efficacy theory (Goddard, Hoy, \& Woolfolk Hoy, 2000; 2004), individual teacher perceptions of collective efficacy as a member of a group, and the potential influence of task analysis as a mediator for the direct effects of group competence perceptions on teacher interactions with students in their classroom.

\section{Theoretical Framework}

Creating change in schools requires the dichotomous actions of both challenging teachers' beliefs, as well as understanding existing beliefs, while providing respect and support during the psychological challenges individuals face throughout the stages of change (Evans, 1996). What are teacher beliefs? In 2012, Fives and Buehl found consistencies across definitions of teachers' beliefs in their review of a large body of psychological literature. Broadly, beliefs are "(a) filters for interpretation, (b) frames for defining problems, and (c) guides or standards for action" (Fives \& Buehl, 2012, p. 478). Beliefs, such as teacher beliefs about collective efficacy, are systems that assimilate and weave together implicitly and explicitly acquired knowledge, judgments, and associated 
affect. Beliefs may also be stable or malleable; beliefs that have been more stable for longer periods of time take longer to shift. In addition, beliefs are often specific to teachers' contexts; teachers may hold one set of beliefs about their classroom practice while teaching but another when reflecting upon their practice. In providing recommendations for future studies, Fives and Buehl (2012) stressed the importance of considering a wide variety of factors and contexts that contribute to teachers' beliefs. Although considered "messy" as a topic for study, Pajares asserted that teacher beliefs can be "the single most important construct in educational research, if properly conceptualized" (1992, p. 329).

\section{Social Cognitive Theory}

Social cognitive theory provides one framework for understanding the role of beliefs in association with context and behaviors. Important aspects of social cognitive theory form the foundation for collective efficacy theory. Social cognitive theory describes a set of essential components of behavioral learning (Bandura, 1986). It is a framework for explaining agency, the interplay between beliefs about possible actions and the true capability of carrying out actions. It is a theory of learning that features the effects of interactions between the behaviors of individuals and groups, reflections on their experiences and attributions, and their environments.

Social cognitive theory advances several key tenets. One key tenet is that people are encouraged to pursue a choice of action after reflecting upon their own cognitive, behavioral, and affective states, as well as contextual circumstances (Bandura, 1986). While individuals commonly reflect upon their own experience to learn and choose subsequent behaviors, observing one's surroundings and the vicarious experiences of 
models in the environment also provides opportunities to reflect and learn. The dynamic nature of social cognitive theory is evident in that it emphasizes how individuals and groups actively impact their environments; likewise, environmental contexts impact individuals and groups.

Another key tenet of social cognitive theory is that the triadic reciprocal interactions taking place between the person or persons, the environment, and chosen behaviors inform the formation of individual beliefs (Bandura, 1986). Individual perceptions, later solidified into beliefs, are the cornerstone for learning and behaving. Individuals' beliefs are linked to the individual's sense of control, aspirations, and behavioral choices. The outcomes of these choices contribute to the individual's learning and confirmation of current beliefs, adjustment, or formation of subsequent beliefs. The theory owes its utilitarian nature to the identification of dynamic interactions between determinants of human agency. This makes social cognitive theory a useful guide when designing interventions for groups and therapeutic approaches for individuals.

At a more detailed level, social cognitive theory describes a set of essential components for behavioral learning (Bandura, 1986). The basic characteristics of human learning capabilities are that people symbolize (make meaning from their experiences and organize that meaning in memory for future use), engage in forethought (planning based on acquired learning), apply vicarious learning to their own practice (focused attention resulting in learning from others' experiences), self-regulate (adjusting behaviors based on personal judgments made about the self), and undergo self-reflection (the exploration of the relationship between learned experiences and one's own capabilities, leading to the 
formation of beliefs about the self and future choice of action). Belief about the self and the capability to act in a given situation is called self-efficacy.

Self-efficacy is an important feature of social cognitive theory. It is the estimation of how successful an individual believes he is likely to be in a situation based on personal experience, skills, and prior learning (Bandura, 1997). However, it is a "guess" based on personal perception and may or may not be an accurate assessment. Social cognitive theory posits that self-efficacy is a better predictor of an individual's future choice of action and level of accomplishment than using an actual measure of the individual's prior skill base and accomplishments. The emphasis on the individual's perception of selfefficacy rather than solely on a factual assessment of skill base and previous accomplishments highlights the motivational aspect of self-efficacy. Simply put, one is more likely to accomplish a task if he has the necessary skills and believes that he can accomplish the task. If he believes the task is beyond his capabilities, an individual is less likely to attempt the task. For example, a preservice teacher may for the first time plan to teach a lesson about an author's use of multiple settings in a story to a small group of fourth graders. At the last minute, however, the teacher may feel that she is not yet capable of correctly structuring a discussion to support understanding of the concept. Instead, she chooses to lead what she perceives to be a simpler lesson on character development. Her supervisor may have reviewed the original lesson about settings with the preservice teacher and felt certain that the novice could successfully explain the lesson's core concepts. However, the teacher's negative sense of self-efficacy prevented her from attempting the lesson. 
Self-efficacy is a determinant of effort, persistence, and resilience (Bandura, 1997). Self-efficacy beliefs affect thoughts, emotions, and future behaviors that can contribute to or erode an individual's level of intrinsic motivation. However, self-efficacy beliefs are malleable, although they are not constantly changing. The relatively stable nature of the construct is part of what makes self-efficacy one predictor of behavioral outcomes. When the term is applied to individual teachers reflecting upon their own potential performance, as in the previous example, self-efficacy is also called teacher efficacy (Tschannen-Moran, Woolfolk Hoy, \& Hoy, 1998). However, groups of teachers working together develop perceptions of their combined capabilities in ways that are similar to the development of teacher efficacy, with outcomes instead associated with group member perceptions of their combined efficacy (Goddard, Hoy, \& Woolfok Hoy, 2000; Goddard, Hoy, \& Woolfolk Hoy, 2004). This is referred to as collective efficacy.

\section{Collective Efficacy}

Collective efficacy theory emerged from social cognitive theory (Bandura, 1997), locus of control theory (Rotter, 1966), and teacher efficacy (Tschannen-Moran, Woolfolk Hoy, \& Hoy, 1998). Locus of control theory differs from social cognitive theory; locus of control theory states that individuals evaluate whether outcomes will be, or were, the result of the individual's behaviors or the result of external, outside influences beyond the control of the individual (Rotter, 1966). At the group level, collective efficacy theory combines both locus of control theory and social cognitive theory with teacher efficacy (Goddard, Hoy, \& Woolfok Hoy, 2000; 2004). Locus of control theory is closely tied to task analysis; social cognitive theory is closely tied to group competence. Members of a group of teachers high in collective efficacy believe that teachers in their school are able 
to successfully help students and contribute to student academic achievement. In contrast, a group of teachers low in collective efficacy operate in an environment of isolation or dysfunction among staff, to the detriment of students. Figure 1 illustrates the theoretical model for collective efficacy, and its components are described in the following section.

Sources of collective efficacy. Goddard, Hoy, and Woolfolk Hoy (2000; 2004) name four sources of collective efficacy beliefs adopted from social cognitive theory (Bandura, 1986; 1997): mastery experience, vicarious experience, social persuasion, and affective state. Mastery experience refers to the perception of group capabilities based on prior experiences of group success or failure, and it is purported to be the strongest source for informing collective efficacy (Bandura, 1997). Vicarious experience is defined as a group's perception of their own capabilities based on observing the performance of another group with similar characteristics. When a group bases the perception of their collective capabilities on verbal or non-verbal feedback received from others or each other, this is social persuasion. Affective state refers to the perception of capabilities based on the reaction elicited by the group when faced by a challenge or crisis. Groups that cope and adapt to challenges are characterized as having functional affective states. Conversely, groups that display negative emotional reactions, avoid, engage in blame, or are incapable of adapting to stressors are characterized as having dysfunctional affective states.

Collective efficacy beliefs typically stem from a combination of two or more of the abovementioned sources working together (Bandura, 1997; Goddard, Hoy, \& Woolfolk Hoy 2000; 2004). Consider a committee of teachers planning a school community night introducing families to the new social and emotional learning (SEL) 
program at Jenkins School. Nearby Baylor School has a similar type of student population and invites the Jenkins committee to visit the Baylor SEL community night. As a result of this visit, the Jenkins committee views themselves as capable of holding their own successful school literacy night, evidence of a vicarious source of collective efficacy beliefs. During the visit, Jenkins teachers speak with Baylor teachers about organizing the community night and assist with facilitating some of the evening activities. Thus, the committee has developed mastery experience to inform their collective efficacy beliefs. When the Jenkins committee returns, they enthusiastically share similarities between successful behaviors that Baylor displayed on community night while indicating that the Jenkins teachers also already possess these capabilities. Here, the Jenkins committee is using social persuasion to help the group believe in their own capacity to host a high-quality community night. This creates a functional affective state that mobilizes positive Jenkins staff efforts to address the challenge of creating a community SEL night. As is commonly the case, multiple sources of collective efficacy beliefs are present in this situation.

Cognitive processing, analyses, and attributions. While experiences are important as sources for shaping collective efficacy beliefs, analyzing and interpreting these experiences is a necessary intermediary step before perceptions can be formed (Goddard, Hoy, \& Woolfolk Hoy, 2000; 2004). Sources of collective efficacy beliefs are appraised by group members before solidifying into perceptions of collective efficacy. Sources undergo analyses, evaluations, attributions, and other similar means of cognitive examination. Two or more individuals experiencing the exact same situation may process the event in different ways, or a group may process the event similarly. Processing often 
takes place through individual self-reflection. This is the reflection preceding learning in social cognitive theory (Bandura, 1986; 1997). However, other means of processing may be more structured, as through conversation or formal activity (Goddard, Hoy, \& Woolfolk Hoy, 2000; 2004). The subjective appraisal by individuals and groups ultimately leads to the formation of perceptions of group collective efficacy.

Group competence and task analysis. The originators of collective efficacy theory view the construct as being comprised of two linked, interdependent components: task analysis and group competence (Goddard, 2002; Goddard, Hoy, \& Woolfolk Hoy, 2000). Task analysis refers to the estimation of how external factors establish task difficulty and to what extent this poses a challenge to collective staff efforts. As an example, teachers perceive high levels of task analysis when parents and community members provide support in working with the school to educate students; the task of educating students seems less onerous to the educational staff. Group competence describes the estimation of the collective educational staff capability to meet student needs. Teachers would perceive high levels of group competence, for instance, if the staff had recently received an award for improving student academic achievement.

To further illustrate the interconnected nature of the two subconstructs, members of a group of teachers high in collective efficacy may also believe that external supports in the community make learning easier for students, creating fewer obstacles for effective instruction; this was previously described as task analysis. When group competence levels are perceived as high, external pressures may seem less daunting to staff which results in positive task analysis perceptions. As external pressures seem less daunting, teachers believe that fewer obstacles exist for staff to support students. If, at the same 
time, teachers on staff hold others' capabilities in high regard, positive group competence perceptions continue to develop. Figure 1 situates this link within the collective efficacy model (Goddard, Hoy, \& Woolfok Hoy, 2004).

Group culture and norms. Collective efficacy perceptions influence normative expectations among teaching colleagues (Goddard, Hoy, \& Woolfolk Hoy, 2004). The group monitors member levels of effort, persistence, and resilience. Over time, a new group member may conform to group culture and established norms for professional behavior, subsequently reflected in behavioral decisions in the classroom and selfreferent perceptions of teaching efficacy. However, if an individual teacher's behaviors and beliefs do not sufficiently align with the group long term, an individual teacher often rejects the social persuasion exerted upon them and leaves to teach elsewhere.

Teacher efficacy. Teacher efficacy develops in ways similar to collective efficacy, but at the individual level and as an assessment of individual capabilities (Tschannen-Moran, Woolfolk Hoy, \& Hoy, 1998). However, as Goddard, Hoy, and Woolfolk Hoy (2004) stated "the sense of collective efficacy in a school can affect teachers' self-referent thoughts and, hence, their teaching performance and student learning” (p. 8). Although teachers operate largely in their own classrooms, they do not fully work in isolation and are susceptible to the social influences of professional colleagues. Goddard and Goddard tested the positive association between collective efficacy perceptions and teacher efficacy in 2001; after accounting for covariates, they found a .25 standard deviation increase in teacher efficacy perceptions for every one standard deviation increase in positive perceptions of collective efficacy. 
Associated outcomes. Appraisals of sources of collective efficacy beliefs feed a sense of achievement, or failure, among the staff and shape the perception of collective efficacy (Goddard, Hoy, \& Woolfolk Hoy, 2000; 2004). Theoretically, the perception of collective efficacy subsequently creates outcomes. Positive or negative outcomes, in turn, establish a foundation for expectations as teachers experience new sources of collective efficacy beliefs, thus completing the cycle in the collective efficacy theoretical model shown in Figure 1.

Few studies have specifically examined teacher outcomes associated with perceptions of collective efficacy. However, Angelle and Teague (2014) found a strong association between collective efficacy and teacher leadership in schools where teachers reported high levels of professional collaboration. Most previous studies of collective efficacy have examined elementary, middle, and high school student academic outcomes associated with collective efficacy levels among groups of teachers (Goddard, 2002; Goddard, Hoy, \& Woolfolk Hoy, 2000; Tschannen-Moran \& Barr, 2004). Both Bandura (1993) and Goddard, Hoy, and Woolfolk Hoy (2000) found that the collective efficacy perceptions of teachers had stronger effects on student achievement than did the socioeconomic status of students. In addition to controlling for socioeconomic status, Goddard, Hoy, and Woolfolk Hoy (2000) also found a strong association between collective efficacy perceptions and student achievement even after controlling for prior student achievement, gender, and race/ethnicity, as well.

\section{Teacher-Student Interactions}

Current research on the quality of teacher-student interactions is rooted in the Process-Product research from the 1960's and 1970's (Brophy, 2006). As the name 
suggests, investigators were interested in finding teaching techniques, or processes, that produced high levels of student achievement as measured by standardized test scores (e.g. Anderson, Everston, \& Brophy, 1979; Good \& Grouws, 1977; Kounin \& Dole, 1975). The goal was to identify a collection of successful instructional approaches effective across teaching contexts, regardless of the subject matter being taught. Teachers today still use many of the approaches identified, such as providing support to elicit correct answers from students and organizing classroom activities to maximize time for student learning. Eventually, as studies in this area produced little new information, researchers moved in another direction (Brophy, 2006).

Process-Product research uncovered the basics of effective instruction and verified the importance of teachers in the role of educating students, as measured by achievement test scores (Brophy, 2006). Broadly, successful teachers created classroom environments that were friendly and welcoming, and students saw these teachers as supportive and enthusiastic. Effective teachers truly believed in their students' ability to be successful while also maintaining a positive sense of their own self-efficacy. Effective teachers maximized instructional time for students as opposed to assigning seatwork, and they addressed learning objectives by creating clear and engaging lessons adapted, as necessary, from available curricular materials. During lessons, teachers also actively engaged students, often by eliciting dialogue about lesson content.

The generic findings from Process-Product research left some questions unanswered, however (Brophy, 2006). What exactly were outstanding teachers doing to elicit from their students deeper and more complex thinking in specific content areas? How was curriculum decided? How were teachers assessing progress? Researchers also 
wanted to know how teachers capitalized upon prior knowledge and skills students brought to classroom lessons. How were teachers encouraging students to create ownership of new learning and apply content knowledge to real-world situations?

As investigators searched for more detailed and thorough answers than those gleaned from the Process-Product studies (Brophy, 2006), researchers required new approaches to understanding teacher and student roles in student learning. The relationship between child and adult, including a student and teacher, guides the development of the child (Bronfenbrenner \& Morris, 1998; Lerner, 1998; Pianta, 1999). Researchers in the 1990's and beyond began applying developmental theory to teacher effectiveness studies as investigators focused on what was happening in the teacherstudent dyad (O’Connor \& McCartney, 2007; Pianta, 1999; Pianta, Hamre \& Stuhlman, 2003). Attention to the whole child, the contexts in which they live, and the importance of relationships between teachers and students became a more prominent part of the conversation about best practices in classrooms. As a result, a significant body of research in education from this era supports the assertion that rich exchanges in positive teacher-student interactions are key for student learning and development (Birch \& Ladd, 1997; Hamre et al., 2013; Pianta, 1999, Pianta, Hamre \& Stuhlman, 2003).

Choice of theoretical perspective in these studies influenced their lines of inquiry and, in turn, methodological choices appropriate to the research task. Systematic observations of teachers and students in classrooms stands as an extremely useful approach for understanding the nature of teacher-student interactions. For example, classroom observations using the CLASS measure (Pianta, Hamre, \& Mintz, 2012), used in the present study, assess teacher-student interactions grounded in an attachment theory 
perspective (Bowlby, 1982), self-determination theory (Connell \& Wellborn, 1991), and developmental systems theory (Lerner, 1998; Pianta, 1999; Pianta, Hamre, \& Stuhlman, 2003). These theoretical perspectives are combined in the Teaching through Interactions theoretical framework, a framework useful for investigating how teachers interact with students and encourage learning by offering emotional support, maintaining an organized and well-managed classroom, and providing instructional support in the creation of positive student outcomes (Hamre et al., 2013). In the next section, I describe these areas of support in greater detail.

\section{Emotional Support}

Emotional support refers to the approaches teachers use during interactions intended to facilitate student social and emotional growth (Hamre et al., 2013; Pianta, Hamre, \& Mintz, 2012). Teachers high in emotional support consciously create a positive emotional tone in the classroom, include student perspectives in activities, honor individual student differences, monitor student emotional needs, and interact in ways that are responsive to the needs of students. Students in these classrooms take risks while seeking support from their teacher, are self-motivated and encouraged to exercise autonomy and leadership, and engage in productive, positive peer interactions under the guidance of the instructor. Emotional support also improves a student's ability to selfregulate and engage in learning tasks (Pianta, 1999). In addition, establishing positive relationships with students enables teachers to more effectively support students in academically stretching themselves as they learn.

Research examining classrooms rich in emotional support show higher cognitive, as well as social and emotional, outcomes for students (Hamre \& Pianta, 2005; Rimm- 
Kaufman, Baroody, Larsen, Curby, \& Abry, 2015). A strong sense of feeling emotionally supported by teachers, as well as parents and peers, has been found to bolster a sense of relatedness in students, resulting in higher levels of classroom engagement for third through sixth grade students (Furrer \& Skinner, 2003). In a study of fifth- and sixth-grade classrooms, student engagement mediated the association between emotional support and standardized achievement (Reyes, Brackett, Rivers, White, \& Salovey, 2012).

\section{Organization and Management of the Classroom}

Classroom organization refers to the ability of the teacher to manage student time, attention, and behavior throughout the day (Hamre et al., 2013; Pianta, Hamre, \& Mintz, 2012). Teachers with strong classroom organization skills are proactive in preventing student distractions from learning, proficient in behavior management, and foster high levels of student productivity. Students show productive engagement in instructional activities, demonstrate their understanding of clear expectations for their tasks and behavior, and are encouraged to use a variety of interesting classroom materials and learning formats to expand their knowledge. Teachers capitalize on the emotional support fostered in dyadic relationships with students and provide expanded support to the group by creating a safe, positive, and organized environment for learning as classmates also interact with one another.

Creating a stable, organized, and supportive classroom environment, while maintaining positive teacher-student relationships, has been linked positively with students' school adjustment and the development of favorable attitudes about school in

students (Birch \& Ladd, 1997). In one study, students from grades 3-5 with high levels of peer exclusion and anxious solitude in the fall of an academic year experienced reduced 
amounts of peer exclusion in the spring; positive classroom emotional climate served as a moderator for student risk of peer exclusion (Avant, Gazelle, \& Faldowski, 2011). Multiple studies (e.g., Ponitz, Rimm-Kaufman, Brock, \& Nathanson, 2009; Raver et al., 2008; Rimm-Kaufman, Curby, Grimm, Nathanson, \& Brock, 2009) have found a strong link between organized, well-managed early-grade classrooms and student self-regulatory control. In addition, multiple studies have found a strong association between the implementation of social and emotional learning programs in classrooms and student academic achievement gains (Durlak, Weissberg, Dymnicki, Taylor, \& Schellinger, 2011).

\section{Instructional Support}

Instructional support refers to teachers fostering student cognitive and language development through a variety of strategies to encourage deep learning (Hamre et al., 2013; Pianta, Hamre, \& Mintz, 2012). This includes purposefully facilitating conversations that promote higher-level thinking skills and extending student responses by offering constructive feedback. Students receive scaffolding and affirmations to guide problem solving and analysis rooted in real-world situations.

However, the findings from studies examining only the provision of instructional support and its association with positive student behavioral and academic outcomes appears mixed. For instance, some work shows no relation between instructional support and engagement, while lower levels of student cognitive self-regulation have been associated with higher levels of instructional support (Rimm-Kaufman et al., 2009). Generally, providing strong instructional support appears linked with positive student outcomes when teachers also provide emotional and/or classroom organizational support. 
One study found that placing at-risk students in classrooms with teachers providing strong instructional, as well as emotional support resulted in end-of-year student achievement scores comparable to those of other low-risk first grade students (Hamre \& Pianta, 2005). Higher student achievement in high school has also been associated with teacher participation in a professional coaching program designed to develop teacher proficiency in the instructional support, emotional support, and classroom organization domains (Allen, Pianta, Gregory, Mikami, \& Lun, 2011).

\section{Current Research}

Teacher-student interaction quality has been studied most carefully in early childhood, though work exists pointing to the importance of these interactions in the elementary, middle and high school grades, as well. One consistent theme in these studies is that teacher-student interactions and relationship quality remained important for academic achievement through fifth grade (Hamre \& Pianta, 2001; Maldonado-Carreno \& Votruba-Drzal, 2011) and into adolescence (Davis, 2003). However, as MaldonadoCarreno \& Votruba-Drzal (2011) pointed out, few studies have specifically examined teacher-student relationships in the upper elementary grades. Of these studies, many investigate the effects of teacher-student interaction quality after the implementation of an intervention program (e.g., Abry, Rimm-Kaufman, Larsen \& Brewer, 2013). More recently, studies place an emphasized focus on the whole teacher as an individual operating within an ecological system, their well-being, and the reciprocal relationship between teacher and student as it affects the quality of teacher-student interactions taking place in the classroom (Pas \& Bradshaw, 2014; Ferguson \& Hirsch, 2014; Jennings \& Greenberg, 2009; Johnson, Kraft, \& Papay, 2012; Split, Koomen, \& Thijs, 2011). This 
line of research returns focus to the important role that teacher beliefs and perceptions of working conditions play in the quality of teacher-student interactions in the classroom.

\section{The Intersection of Study Constructs}

Findings from previous studies identifying the positive association between collective efficacy perceptions and student outcomes (Goddard, 2002; Goddard, Hoy, \& Woolfolk Hoy, 2000; Tschannen-Moran \& Barr, 2004), as well as collective efficacy and teacher efficacy (Tschannen-Moran, Woolfolk Hoy, \& Hoy, 1998). These studies assert that collective efficacy is a pre-existing construct influencing teacher and student outcomes (Bandura, 1997; Goddard, Hoy, Woolfolk Hoy, 2000; 2004) and is critically in need of further investigation (Pajares, 1997). The present study investigates an important, yet unexplored, association within the collective efficacy theoretical cycle by asking: To what extent are an individual teacher's perceptions of collective efficacy associated with instructional quality, as determined by the nature of teacher-student interactions in their classroom? Here is an investigation of the critical point where collective efficacy perceptions may link with academic outcomes via contact between the teacher and their students. However, prior to this investigation, I must confirm the factor structure of the collective efficacy construct, called into question by previous studies with conflicting results. Therefore, a thorough understanding of the theoretical foundations for the current study is doubly important.

Collective efficacy theory, as conceived for teachers by Goddard, Goddard, and Hoy $(2000 ; 2004)$, is a useful framework for thinking about how teachers' learning, teachers' beliefs, their estimated degree of control over outcomes, and their behavioral choices influence instructional quality in classrooms. Collective efficacy theory also 
organizes perceptions of teacher working conditions into internal (group competence) and external (task analysis) resources and detriments to group capabilities for fostering successful student outcomes. The theory unites social cognitive theory (Bandura, 1986) and locus of control theory (Rotter, 1966) into a thorough explanation of the power of teachers' beliefs.

Singularly, social cognitive theory (Bandura, 1986) and locus of control theory (Rotter, 1966) offer helpful but incomplete explanations for the link between teacher beliefs and student outcomes. Social cognitive theory posits that humans learn constantly as they reflect upon their experiences, choose future actions based upon the possibility of achieving successful outcomes, and dynamically interact with their environments (Bandura, 1986; 1997). Social cognitive theory can be very useful for understanding how collective efficacy contributes to teacher-student interactions in the classroom. However, social cognitive theory falls short because it does not explain what can happen in the presence of perceived obstacles and supports in the workplace.

The ongoing learning process described by social cognitive theory (Bandura, $1986 ; 1997)$ is affected by how teachers estimate the degree of difficulty for achieving successful outcomes with students (e.g., appraisal of task difficulty). Teachers ask "What are the obstacles to doing this? And what support are we getting?" This way of thinking is at the heart of locus of control theory (Rotter, 1966). This is a process of gauging effectiveness based on weighing internal factors and capabilities against external factors serving as supports and challenges. However, locus of control theory does not consider the nature of how teacher experiences inform teacher learning and reflection prior to teachers' assessments of whether they possess enough power to achieve subsequent 
goals. Therefore, collective efficacy theory incorporates principles of both social cognitive theory as well as locus of control theory in its explanation of how teachers' perceptions of working conditions influence teacher behaviors in the classroom and affect student outcomes (Goddard, Hoy, \& Woolfolk Hoy, 2000; 2004).

Each teacher holds individual perceptions of collective efficacy as a member of the group of teachers at a school. This study is unique in considering individual perceptions of collective efficacy and their association with teacher-student interaction quality. For the purposes of this study, teachers ask, "How competent do I think my teaching teammates are? And what do I believe are the obstacles and supports we encounter as we educate our students?" This investigation links the answers to these questions with the ways in which each teacher interacts with their students in the classroom.

Some hypothesized influences of collective efficacy on instructional quality are obvious. Collective efficacy perceptions shape the norms and expectations of the group which, in turn, influences the instructional quality of the individual teacher in the classroom. For example, as a member of a group of teachers who view themselves as experts continually sharing and applying educational research findings about classroom instruction, the individual teacher will perform at a high level to match group selfperceptions. As another example, even with positive self-perceptions, the group may believe that too many obstacles (such as a lack of instructional time or weak administrative support) prevent the facilitation of successful student outcomes in the classroom. Thus, the individual teacher may also lower his or her expectations regarding success with students. 
We can examine the potential link between collective efficacy and instructional quality on a more detailed level by unpacking teacher-student interactions as viewed through the Teaching through Interactions model. A positive sense of collective efficacy on staff would facilitate professional support and development among staff members, including the sharing of direct knowledge pertaining to high-quality instruction within the three domains of the Teaching through Interactions model. Indirectly, positive collegial relationships may help reduce teacher stress and, in turn, improve a teacher's ability to provide emotional support to students. As mentioned earlier, emotional support and healthy teacher-student relationships in the classroom are the cornerstones for highquality instruction across all domains of the Teaching through Interactions model.

\section{Summary}

The present chapter explained theoretical frameworks supporting the hypotheses set forth in Chapter 1 and provided examples of prior research applying these theories. I discussed the origins of collective efficacy theory (Goddard, Hoy, \& Woolfolk Hoy, 2000; 2004), from social cognitive theory (Bandura, 1986) and locus of control theory (Rotter, 1966). I also described how teacher perceptions of working conditions are organized within collective efficacy theory. In addition, I provided background information to explain the association between collective efficacy and instructional quality. Then I established the theoretical basis for using the nature of teacher-student interactions to define instructional quality in the classroom. Specifically, I discussed the Teaching through Interactions theoretical framework (Hamre et al., 2013), the three domains of teacher-student interactions within the framework, and examples of research studies linking teacher-student interactions with student outcomes. In doing so, 
information provided in this chapter further clarified the established premise of the present study while providing the theoretical basis for methodological choices set forth in the next chapter. 


\section{CHAPTER THREE}

\section{METHOD}

The previous chapter situated the constructs of collective efficacy, group competence, and task analysis under the framework of social cognitive theory, described the body of previous research pertaining to teacher working conditions, and clarified common criteria for high-quality instruction as measured by the nature of teacher-student classroom interactions. As noted, previous studies have added to an understanding of each of these areas. However, collective efficacy theory requires additional testing, and the strength of collective efficacy's association with observed teacher-student classroom interactions remains to be explored.

The present study employed factor analysis to address the potential presence of collective efficacy, group competence, and task analysis in a commonly-used measure of teacher perceptions of working conditions. After gathering descriptive statistics for these constructs, I examined the strength of association between the constructs and observation scores for teacher-student classroom interactions using structural equation modeling. The contents of this chapter further describe the context of the study, participant characteristics, procedures for data collection and measures, and methods for the analysis of data. 


\section{Research Design}

This study used cross-sectional panel data for an exploratory investigation testing the viability of collective efficacy's theoretical constructs and the strength of their association with observed scores for teacher-student interactions in the classroom. It is a one-level design examining individual teacher perceptions of collective efficacy reported via surveys, as well as scores collected from multiple observations of the same teachers interacting with students in classrooms. Therefore, the individual classroom teacher is the unit of analysis.

Data come from Year 1 of the MET Project study (2009-2010). The purpose of the Year 1 data collection was to gather data to be used in future exploratory and descriptive studies, such as the investigation described in this dissertation (Bill \& Melinda Gates Foundation, 2013a; Kane, Kerr, \& Pianta, 2014). Descriptive information were compiled to illustrate central tendency and variation in teachers' survey responses. I hypothesized one of two possible outcomes from analyses testing the factor structure of collective efficacy — a one-factor model or a two-factor model. Figure 5 shows the structural equation model for testing the direct association between collective efficacy and teacher-student interaction quality if a one-factor model emerged.

Figure 6 shows the structural equation model for a two-factor outcome, testing whether task analysis mediates the relation between group competence and each domain of teacher-student classroom interactions. Although the present study used survey data from only one time-point, evaluating a model with task analysis as a mediator for the effects of group competence on teacher-student interactions corresponded to existing theory about the relation between the two constructs (as previously explained) and fit 
with the study's goals. In tests of mediation, researchers commonly use longitudinal data to understand how a construct emerging over time (the mediator) changes the effect of a baseline predictor on an outcome variable. However, I examined whether a construct already existing in the panel data (task analysis) would mediate the direct effect of group competence on teacher-student interaction quality. Thus, mediation analysis in the present study is a theoretical investigation of coexisting constructs.

\section{Context of the Study}

MET Study. Conducted from 2009-2011, the MET Project was sponsored by the Bill \& Melinda Gates Foundation in collaboration with several academic and research institutions. The MET Project involved data collection from approximately 3000 grade 49 teachers in six school divisions across the United States (Bill \& Melinda Gates Foundation, 2010; 2013a; Kane, Kerr, \& Pianta, 2014). To date, this was the largest investigation of teaching effectiveness ever undertaken in the U.S. The goal of the project was to determine the most accurate combination of teacher evaluation measures to support future efforts to identify and develop high-quality instructional methods. Participants were not randomized in the first year of the study (2009-2010), and data were intended for use in exploratory and descriptive investigations. Participants were randomized in the second year of the study and data collected were analyzed to determine causal effects of teaching behaviors on student outcomes. The Inter-university Consortium for Political and Social Research houses the data. 


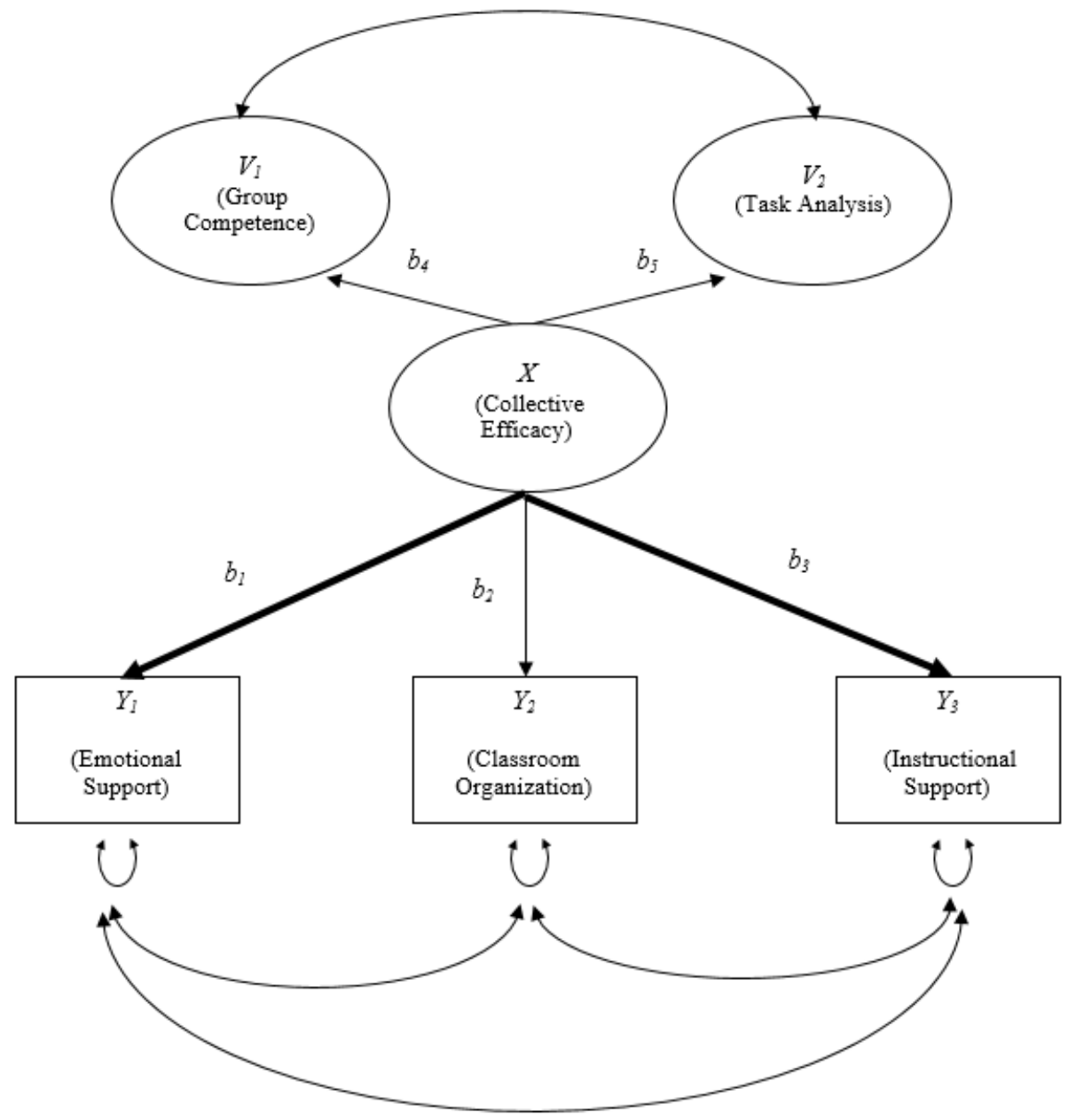

Figure 5. Hypothesized $(\mathrm{H} 3 a)$ structural regression path model showing the direct effects of collective efficacy on each of the three CLASS domains. Ovals represent latent variables. Rectangles represent observed variables. Bold lines indicate hypothesized significance. 


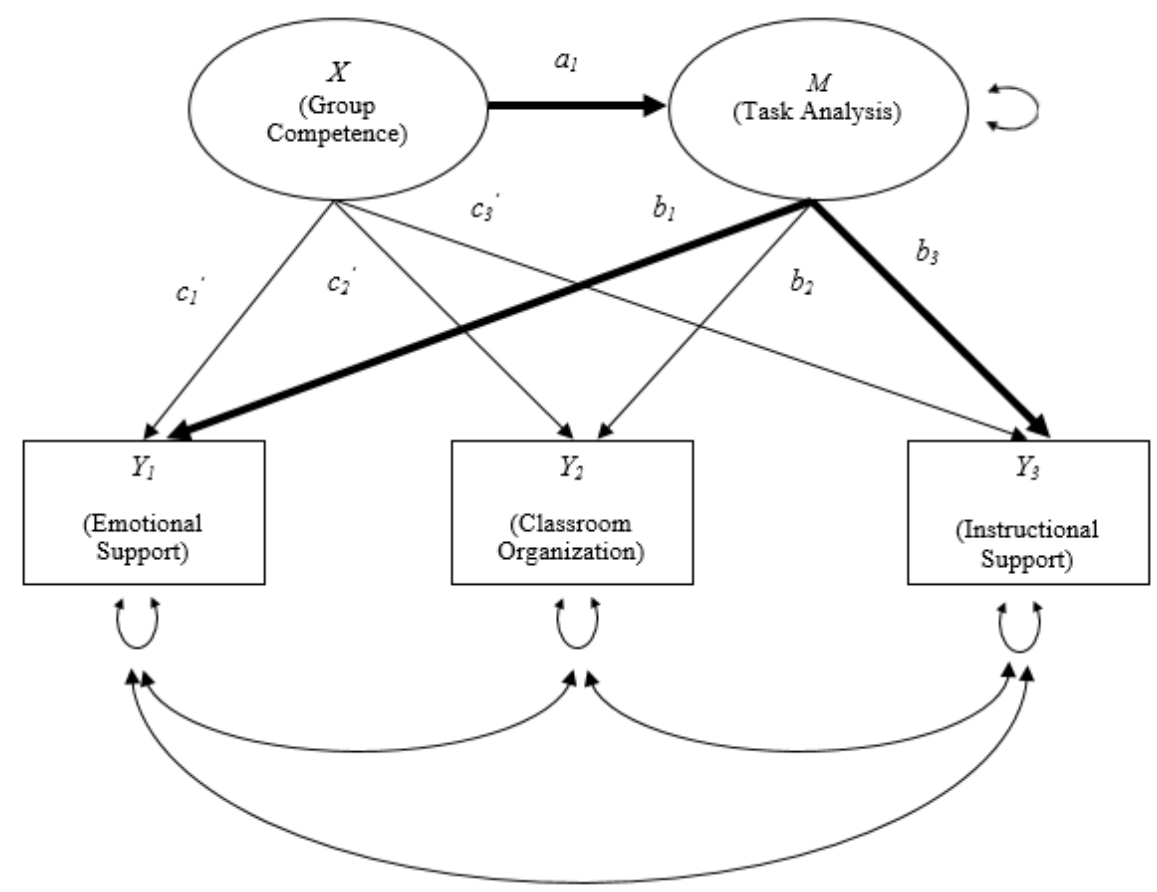

Figure 6. Hypothesized $(H 3 b)$ structural regression path model with task analysis mediating the effect of group competence on each of the three CLASS domains (Emotional Support, Classroom Organization, and Instructional Support). Ovals represent latent variables. Rectangles represent observed variables. Bold lines indicate hypothesized significance. 
The present study. The University of Virginia Institutional Review Board for the Social \& Behavioral Sciences provided approval for this study for a period of four years, beginning in July of 2014. As stewards of the MET Project data, the Inter-University Consortium for Political and Social Research (ICPSR) required that a confidential use and data security agreement be signed by the University Associate Vice President for Research and Project Investigator. The security agreement was submitted to ICPSR along with documentation of IRB approval, the ICPSR application request for MET Project data use, and an annual fee for data lease (Bill \& Melinda Gates Foundation, 2013b).

The study featured in this dissertation sought to use the MET Project data to achieve three aims. The first aim was to confirm or reject the hypothesized factor structures for collective efficacy potentially present in the TWC survey instrument. The second aim was to gather descriptive data for teacher perceptions of their working contexts, specifically for collective efficacy. Finally, the third aim was to determine how, and the extent to which, teacher perceptions of collective efficacy relate to observed levels of teacher-student interaction quality (i.e., emotional support, classroom organization, and instructional support).

The TWC survey included six items from the collective efficacy scale created by Goodard, Hoy and Woolfok Hoy (2000). Given the presence of these items, it was likely that the construct of collective efficacy and/or the subconstructs of group competence and task analysis would emerge as factors in the data. The TWC survey was constructed more recently than the older collective efficacy scale. The broad body of MET data includes TWC responses and classroom observation scores for individual teachers, affording the 
opportunity to explore teacher perceptions as psychological constructs and their relation to teacher-student interactions in the classroom.

\section{Participants}

Fourth and fifth grade mathematics, language arts (ELA), and ELA and mathematics teachers $(n=392)$ employed by five large school districts in 105 schools across the United States completed surveys and classroom observations during the MET Project from 2009-2010. Three of these school districts are located in the Southeastern region of the United States, one in the Mid-Atlantic, one in the Southwest, and one in the Western region. The research team recruited volunteer schools from participating districts, then recruited teachers from targeted grades and subjects. Table 1.1 displays teacher participant characteristics. Table 2.1 shows frequency counts for the number of teachers corresponding to the percentage of students with specific characteristics in their classrooms. For example, 58 teachers, or $14.8 \%$ of the participant sample, had a classroom (or an average of their two sections) with 60-70\% White students. Teachers were included in the present study if they completed the CLASS observations (number of observations varied; most teachers completed four) and the TWC survey were included in the present study. 
Table 1.1

Descriptive Characteristics of the Sample

\begin{tabular}{|c|c|c|}
\hline Characteristic & Frequency & Percentage \\
\hline \multicolumn{3}{|l|}{ Gender } \\
\hline Female & 348 & 89 \\
\hline Male & 34 & 9 \\
\hline \multicolumn{3}{|l|}{ Race } \\
\hline White & 230 & 59 \\
\hline Black & 129 & 33 \\
\hline Hispanic & 19 & 5 \\
\hline Other & 4 & 1 \\
\hline \multicolumn{3}{|l|}{ Grade Taught } \\
\hline 4 th & 185 & 47 \\
\hline 5 th & 207 & 53 \\
\hline \multicolumn{3}{|l|}{ Subject Taught } \\
\hline ELA & 73 & 19 \\
\hline Math & 42 & 10 \\
\hline ELA+Math & 277 & 71 \\
\hline \multicolumn{3}{|l|}{ Number of Sections Taught } \\
\hline One & 333 & 85 \\
\hline Two & 59 & 15 \\
\hline \multicolumn{3}{|l|}{ Degree earned } \\
\hline Master's or more & 129 & 33 \\
\hline Bachelor's or less & 176 & 45 \\
\hline Experience & $\begin{array}{c}\text { Total } \\
\text { (Frequency) }\end{array}$ & $\begin{array}{c}\text { In Current } \\
\text { District } \\
\text { (Frequency) }\end{array}$ \\
\hline First Year & 12 & 51 \\
\hline 2-3 Years & 46 & 60 \\
\hline 4-6 Years & 73 & 69 \\
\hline 7-10 Years & 97 & 53 \\
\hline 11-20Years & 119 & 38 \\
\hline $20+$ Years & 44 & 9 \\
\hline
\end{tabular}

Note. $N=392$. In some categories, the percentage of responses are less than $100 \%$ due to missing data. 
Table 2.1

Frequency of teachers in the sample with the following classroom characteristics

\begin{tabular}{|c|c|c|c|c|c|c|c|c|c|c|c|c|}
\hline & \multicolumn{2}{|c|}{$\begin{array}{c}<20 \% \text { of } \\
\text { Students in } \\
\text { Class }\end{array}$} & \multicolumn{2}{|c|}{$20 \%-39 \%$} & \multicolumn{2}{|c|}{$40 \%-59 \%$} & \multicolumn{2}{|c|}{$60 \%-79 \%$} & \multicolumn{2}{|c|}{$\begin{array}{c}>80 \% \text { of } \\
\text { Students in } \\
\text { Class }\end{array}$} & \multicolumn{2}{|c|}{$\begin{array}{c}\text { Missing } \\
\text { Data }\end{array}$} \\
\hline & $\mathrm{n}$ & $\%$ & $\mathrm{n}$ & $\%$ & $\mathrm{n}$ & $\%$ & $\mathrm{n}$ & $\%$ & $\mathrm{n}$ & $\%$ & $\mathrm{n}$ & $\%$ \\
\hline \multicolumn{13}{|l|}{ Gender } \\
\hline Male & 1 & 0.26 & 32 & 8.16 & 302 & 77.04 & 56 & 14.29 & 1 & 0.26 & 0 & 0.00 \\
\hline Female & 1 & 0.26 & 56 & 14.29 & 294 & 75.00 & 40 & 10.20 & 1 & 0.26 & 0 & 0.00 \\
\hline \multicolumn{13}{|l|}{ Race } \\
\hline White & 208 & 53.06 & 59 & 15.05 & 40 & 10.20 & 58 & 14.80 & 27 & 6.89 & 0 & 0.00 \\
\hline Black & 194 & 49.49 & 59 & 15.05 & 31 & 7.91 & 37 & 9.44 & 71 & 18.11 & 0 & 0.00 \\
\hline Hispanic & 237 & 60.46 & 86 & 21.94 & 42 & 10.71 & 20 & 5.10 & 7 & 1.79 & 0 & 0.00 \\
\hline Asian & 362 & 92.35 & 24 & 6.12 & 6 & 1.53 & 0 & 0.00 & 0 & 0.00 & 0 & 0.00 \\
\hline Other & 388 & 98.98 & 4 & 1.02 & 0 & 0.00 & 0 & 0.00 & 0 & 0.00 & 0 & 0.00 \\
\hline ELL & 305 & 77.81 & 58 & 14.80 & 22 & 5.61 & 6 & 1.53 & 1 & 0.26 & 0 & 0.00 \\
\hline $\begin{array}{l}\text { Free or reduced- } \\
\text { price lunch }\end{array}$ & 77 & 19.64 & 104 & 26.53 & 51 & 13.01 & 35 & 8.93 & 28 & 7.14 & 97 & 24.74 \\
\hline
\end{tabular}

\section{Data Collection Procedures}

Surveys were completed using a confidential online system between March and May of 2010. Teacher observations were recorded at times spread out between February and June of 2010. Subject matter generalists were recorded teaching both Mathematics and ELA in two separate lesson sessions, each at least 30 minutes long, on four separate days in the five-month recording window. Two separate lesson sessions over two days were recorded for subject specialists during this time. Teachers were asked to teach a lesson of their own choosing in half of the recorded sessions. In the other half of the recorded sessions, teachers selected a lesson topic from a list of choices provided by the 
MET Project. Teachers were trained in recording their lessons and responsible for uploading videos to the MET Project online video portal. Each participating teacher received $\$ 1000$ at the beginning of the study and $\$ 500$ upon concluding.

\section{Measures}

Teacher Working Conditions Survey (TWC). The TWC consists of nine scales and a total of 232 items (Bill \& Melinda Gates Foundation, 2013b). Teachers provided feedback regarding the amount of time to carry out duties, the quantity and quality of facilities and resources, community support and involvement, student conduct, teacher leadership, school leadership, professional development, and instructional practice and support. Sample items from the survey include, "Local assessment data are available in time to impact instructional practices" and "Teachers work in professional learning communities to develop and align instructional practices." Answer options are on a 5point scale, 1 = Strongly Disagree, $2=$ Disagree, $3=$ Agree, $4=$ Strongly Agree and $5=I$ Don't Know.

\section{The Classroom Assessment Scoring System - Upper Elementary (CLASS).} The CLASS instrument (Pianta, Hamre, \& Mintz, 2012) is an observational tool for scoring teacher support of academic and social development in the classroom. The scoring rubric is divided into three primary domains consisting of dimensions with descriptive indicators for guiding observational ratings. Dimensions for the Emotional Support domain $(\alpha=.84)$ include Positive Climate, Negative Climate, Teacher Sensitivity, and Regard for Student Perspectives. The dimensions for the Classroom Organization domain $(\alpha=.79)$ are Behavior Management, Productivity, and Instructional Learning Formats. The Instructional Support domain $(\alpha=.92)$ dimensions include 
Content Understanding, Analysis and Problem-Solving, Instructional Dialogue, and Quality of Feedback. Although a new dimension for the Instructional Support domain, Student Engagement, was introduced for the CLASS-Upper Elementary manual used in the MET Project study, this dimension is considered student-centered and was excluded for the present study. Raters score dimensions within each domain on a 7-point scale (Low (1-2), Mid (3-5), and High (6-7)).

MET Project CLASS raters scored 15-minute video segments, taken from the beginning of each lesson. CLASS raters were current and former teachers trained online through the CLASS website, previously designed by program developers. Training was self-directed, lasted up to 25 hours, and concluded when coders passed a certification test. As a means of maintaining reliability over time, raters practiced scoring with a calibration video at the start of each scoring session. No rater scored any video of a teacher from his or her district. Kane and Staiger (2012) report that reliabilities fell between .14 and .37 for single observations by single observers in the MET Project Study, but reliability improved when scores from multiple observations were averaged together.

Approximately 5\% of the videos were scored by two raters. Appendix B shows MET Project double-coding reliability figures for each dimension of the CLASS (Pianta, Hamre, \& Mintz, 2012). The percent exact match ranged from 26.6 to 67.5 , and the percent of exact match within one point ranged from 67.9 to 95.1. ICCs ranged from .26 to .49. Miles, Huberman, and Saldana (2014) recommend that coding agreement fall between $85 \%$ and $90 \%$; standards for interpreting interrater agreement estimates categorize an ICC of .26 as a lack of agreement and an ICC of .49 as weak agreement (LeBreton \& Senter, 2008). Although the reliability of the domains was not reported, we 
would expect the domain reliability to be higher because the average of the set of dimensions will always be more reliable than an individual dimension. Data were also unavailable for calculating domain reliability.

Analyses in the present study used a mean CLASS dimension score and mean domain score for each teacher. CLASS dimension scores in the MET dataset are reported for each class section as means calculated from approximately four observations throughout the year (Kane, \& Staiger, 2012). Therefore, a teacher might teach one class section a day, and the dataset would show one Positive Climate dimension score, one Negative Climate dimension score (and so on) for each section taught. Fifty-nine of 392 teachers in the dataset taught two sections. For these 59 teachers, I calculated a single dimension score by averaging the dimension scores from the two sections. The three domain scores for each teacher was calculated by averaging the dimension scores relevant to each domain.

\section{Analytic Approach}

\section{Data Screening}

MET data were accessed and analyzed via the ICPSR virtual enclave. Data for the present study were cleaned and initially screened using Stata 13 software (StataCorp, 2013) and SPSS 20.0 (IBM Corp, 2011). Two data cleaning details require mention. TWC items answered with a " 5 " indicating I Don't Know were counted as missing data. Also, structural equation modeling required reverse coding of the Negative Climate dimension scores in the Emotional Support Domain.

Standard tests of linearity, normality, homoscedasticity, skewness and kurtosis values, and residual plots were reviewed to test assumptions. Data met necessary 
assumptions. Analyses performed to investigate research questions were conducted using version 7.4 of the Mplus statistical package (Muthen \& Muthen, 2012) because it employs full information maximum likelihood (FIML) estimation that helps preserve sample size (Little \& Rubin, 1987) and minimizes parameter estimate bias (Enders, 2001). FIML assumes that data are missing at random which means that missingness on a variable is not related to values on that variable, although it could be related to values on other variables in the model. Exploration of missing data patterns did not reveal any reasons for missingness that would imply that the data were not missing at random. There were no missing data for the dependent variable, CLASS domain scores. Data were treated as continuous in analyses.

\section{Collective Efficacy Item Selection}

I selected an initial pool of 78 items from the MET Project TWC survey to create a measure of collective efficacy for the present study. This selection included six items that had previously been part of the original long form of the Collective Efficacy Scale (Goddard, Hoy, \& Woolfolk Hoy, 2000) (Appendix A). Other items selected from the TWC survey were theoretically plausible indicators of collective efficacy and had the potential to form the basis for an updated, thorough assessment of contemporary collective efficacy perceptions appropriate to the evolution of school working contexts since the creation of the original scale (Goddard, Hoy, \& Woolfolk Hoy, 2000). For example, multiple TWC items asked respondents about the nature of teacher collaboration in schools (an indicator resembling group competence). This may stem from the increased prevalence of teacher collaboration (Goddard, Goddard, \& Tschannen-Moran, 2007; Moolenaar, 2012). 
All six original Collective Efficacy Scale items (Goddard, Hoy, \& Woolfolk Hoy, 2000) were kept for the final measure used in this study. Four criteria guided the process of removing other items from the selection pool. A survey of the original selected items was sent to six consultants with expertise in the field of education research to request feedback regarding how the items would potentially be categorized: as either an estimation of task analysis, group competence, neither, or unsure. I also compiled a table of bivariate correlations for the 78 items. Items were removed if they lacked any significant correlations with other items at the level of $p<.05$, and $r<.40$ or $r>.79$. Additional items were removed if the feedback survey results showed less than $80 \%$ agreement among consultants regarding the categorization of an item. At the end of this reduction process, twenty items remained for factor analyses.

Using the random number generator in SPSS, teachers in each district were given numbers and each district was split for analyses with odd- and even-numbered groups. Even-numbered teachers from all districts comprised one group, and odd-numbered teachers from all districts comprised the other group. As a result, half of the sample data were used for exploratory analyses, and one-half were used for confirmatory analysis.

\section{Exploratory Factor Analyses}

Researchers use exploratory factor analyses to explore and refine theory and use confirmatory factor analysis for theory confirmation (Stevens, 2009). The twenty items selected for factor analyses had never been combined together into a scale, or scales, for collective efficacy. The purpose of the exploratory factor analyses was to test whether the shared variances of these items would support either a two-factor structure with group 
competence and task analysis as distinct constructs or support a one-factor structure for collective efficacy.

Conducting exploratory factor analyses was a necessary preparatory step for confirming the underlying factor structure of collective efficacy. The results were also compared with the findings of Goddard and colleagues (2000), who did not conduct a confirmatory analysis to verify a single-factor structure for collective efficacy. The authors instead used a form of exploratory factor analysis, principal axis factoring results with an orthogonal varimax rotation, which does not allow for potential correlation between group competence and task analysis (Goddard, Hoy, \& Woolfolk Hoy). Item reduction to refine a one-factor scale was the primary goal. I used exploratory factor analyses with oblimin rotation, a commonly used type of oblique rotation, to broaden the chance for the emergence of either a one- or two-factor structure. Also, given that group competence and task analysis are described as interrelated in Collective Teacher Efficacy Theory, I used an oblique rotation to allow for correlation between the constructs if they emerged separately (Brown, 2015). Oblique rotation also allows for an orthogonal solution to manifest in the event that factors are not correlated, as previously assumed (Bandalos \& Finney, 2010).

In the process of preparing a collective efficacy model for confirmatory factor analysis, I conducted exploratory factor analyses for possible one- and two-factor solutions and removed one item at a time to improve fit while preserving theory (Bandalos \& Finney, 2010), described later in more detail. As a guideline, the number of factors divided by the number of indicators (items) should be less than .30 (Hakstian, Rogers, \& Cattell, 1982). Mueller and Hancock (2010) also recommend using four to six 
indicators of reasonable quality per factor (2010). Thus, the objective was to retain at least four to six indicators for a one-factor solution or at least eight to twelve indicators for a two-factor solution. On the first run, Kaiser's rule (1960) for examining the number of factors with eigenvalues $\geq 1.00$ was used to ensure that the variance of one indicator was not more than the variance explained by a factor included in the model. The number of eigenvalues $\geq 1.00$ also guided the number of recommended factors for inclusion in the final model.

Model fit indices were important guides for interpreting exploratory factor analyses, confirmatory factor analysis, and structural equation modeling results. As individual items were removed for each iteration of exploratory factor analysis, model fit statistics for both the potential one-factor solution and the two-factor solution were interpreted. I examined the three types of standard goodness-of-fit indices: absolute, parsimonious, and comparative fit indices (Brown, 2015; Mueller \& Hancock, 2010; Klein, 2011). Absolute fit indices such as the $\chi^{2}$ statistic and the Standardized Root Mean Squared Residual (SRMR) were used to evaluate the overall difference between observed and model-implied variances and covariances. For both statistics, smaller numbers are better; $\chi^{2}$ values range from 0.00 , as a perfect fit, to 1.00 and SRMR values should be less than .08 (Hu \& Bentler, 1999). The Root Mean Squared Error of Approximation (RMSEA) and Akaike Information Criterion (AIC) were used as parsimonious fit indices that evaluate model simplicity while comparing the observed and hypothesized models. RMSEA values of .06 or lower are preferred, values between .061 and .08 are acceptable, and values greater than .10 indicate poor, unacceptable model fit (Brown \& Cudeck 1993). AIC values are useful descriptors of fit when nesting does not occur in the model, 
as in this case; smaller values are more desirable (Mueller \& Hancock, 2010). Bentler's comparative fit index (CFI) and the Tucker-Lewis Index (TLI) gauge the overall absolute fit compared to the baseline model. For the CFI and TLI, values of .90 or greater are considered good model fit; values of .95 or more are ideal (Hu \& Bentler, 1999).

Analyzing exploratory factor analysis results and the process of removing items to improve model fit involved the following steps. First, model fit indices were examined to verify improvement after the removal of each indicator. Then a potential item for removal was selected based on low and/or non-significant pattern coefficient loadings (Brown, 2015). Next, I consulted the estimated residual variance list to see whether the item had a high value. If retaining the item was theoretically logical based on the relationship to other retained items, it was not removed. The process concluded when model fit values indicated adequate fit based on the criteria explained previously. The final model was subsequently verified by conducting a confirmatory factor analysis.

\section{Confirmatory Factor Analysis}

Confirmatory factor analysis using the Mplus was conducted to answer RQ1 (Figure 2), determining whether collective efficacy is a factor unto itself or whether collective efficacy is comprised of two distinct factors, group competence and task analysis.

\section{Descriptive Analysis}

I gathered descriptive statistics to answer RQ2 and understand teachers' perceptions of group competence and task analysis. Descriptive statistics included means, ranges, and standard deviations for collective efficacy constructs and CLASS dimensions. 
Bivariate correlations of collective efficacy constructs with CLASS dimensions were also analyzed for relationship patterns.

\section{Structural Equation Modeling}

Structural equation modeling was conducted to answer RQ3, examining the extent to which collective efficacy relates to each CLASS domain. Structural equation modeling was appropriate given the presence of both latent and observed variables in the analysis (Kline, 2011). Figure 6 shows the hypothesized relation of the two-factor structure for collective efficacy with teacher-student interaction quality. Two structural equation models were established. The first model assessed the direct effects of collective efficacy on each of the three CLASS domains: Emotional Support, Classroom Organization, and Instructional Support. The second model examined the extent to which task analysis mediated the relation between group competence and each of the three CLASS domains using bootstrapping (Bollen \& Stine, 1992). Fit statistic guidelines previously discussed were also appropriate for structural equation model testing. Covariates were not included in the model for two reasons. First, the study is exploratory in nature. Second, Bentler and Chou (1987) recommend having a ratio of five sample subjects for every free parameter in a structural equation model to ensure reliable estimations of model fit. The small sample size means that including covariates would have reduced analytic power and produced poorer model fit as the number of parameters increased. 


\section{CHAPTER FOUR}

\section{RESULTS}

This study investigated the extent to which fourth- and fifth-grade teachers' perceptions of collective efficacy relate to the quality of student-teacher interactions. Three research questions guided analyses. First, I identified the underlying structure of the collective efficacy construct using confirmatory factor analysis. Second, I described how individual teachers in the sample perceived the competence of their teaching teammates as a group and how individual teachers viewed the obstacles and supports faced by the team. Finally, I used structural equation modeling to examine the association between individual teacher perceptions of group competence and task analysis and the observed quality of teacher-student interactions in the classroom. The present chapter contains a detailed explanation of these findings.

\section{Exploratory Factor Analysis}

Following Kaiser's rule (1960), eigenvalues $\geq 1.00$ in the first EFA, 4.523 and 1.729 , indicated that all nine items explained $69.47 \%$ of the variance when loaded on to two factors. Although this finding required further confirmation, it suggested a two-factor structure underlying collective efficacy. None of the fit indices for a possible one-factor solution attained acceptable values in the eleven iterations of exploratory analyses. Model fit for a two-factor solution gradually improved as selected items were removed one at a time and analyses were run again. For example, the model fit indices from the first 
analysis were $\mathrm{CFI}=.874, \mathrm{TLI}=.841, \mathrm{RMSEA}=.069$, and SRMR $=.081$. Subsequently removing the item "Teachers take responsibility for helping one another do well" was based on low pattern loadings of -.078 and .307 $(p<.05)$ and a high estimated residual variance of .913 . The removal of additional items for the remaining analyses followed a similar process, previously described. Table 3.1 shows final fit indices for the one- and two-factor exploratory factor analyses of the items listed in Table 4.1. Table 4.1 also shows final factor loadings from the confirmatory factor analysis, described below.

Table 3.1

Exploratory and confirmatory analysis models

\begin{tabular}{|c|c|c|c|}
\hline & $\begin{array}{c}\text { EFA 1-Factor } \\
\text { Model }\end{array}$ & $\begin{array}{c}\text { EFA 2-Factor } \\
\text { Model }\end{array}$ & $\begin{array}{c}\text { CFA 2-Factor } \\
\text { Model }\end{array}$ \\
\hline AIC & 1539.00 & 1491.60 & 1721.57 \\
\hline CFI & .78 & .96 & .92 \\
\hline TLI & .71 & .93 & .88 \\
\hline \multicolumn{4}{|l|}{ RMSEA } \\
\hline Estimate & .11 & .06 & .07 \\
\hline $90 \%$ C.I. & $.09-.14$ & $.01-.09$ & $.04-.10$ \\
\hline $\begin{array}{l}\text { Probability } \\
\text { RMSEA <= }=.05\end{array}$ & .00 & .35 & .14 \\
\hline \multicolumn{4}{|l|}{ 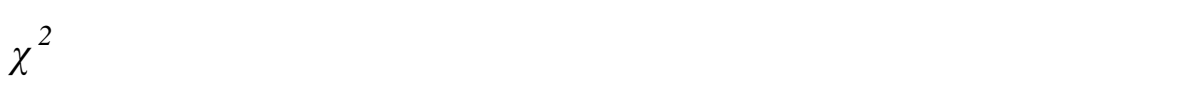 } \\
\hline Estimate & 94.03 & 30.63 & 50.03 \\
\hline$d f$ & 27 & 19 & 26 \\
\hline$p$-value & .00 & .04 & .00 \\
\hline SRMR & .14 & .05 & .08 \\
\hline
\end{tabular}

Note. AIC $=$ Akaike Information Criterion $; \mathrm{CFI}=$ comparative fit index $; \mathrm{TLI}=$ TuckerLewis index; RMSEA = root mean square error of approximation $(90 \%$ confidence interval); SRMR = standardized root mean square residual. 
Table 4.1

Retained Teacher Working Conditions Survey items and standardized factor loadings

\begin{tabular}{|c|c|c|}
\hline & Item & $\begin{array}{l}\text { Standardized } \\
\text { factor loading }\end{array}$ \\
\hline \multicolumn{3}{|l|}{ Task analysis } \\
\hline$* \mathrm{TAR}$ & Our students come to school ready to learn. & .79 \\
\hline TAP & $\begin{array}{l}\text { Parents/guardians support teachers, contributing to their success with } \\
\text { students. }\end{array}$ & .60 \\
\hline TAE & The faculty work in a school environment that is safe. & .68 \\
\hline TAL & The school leadership consistently supports teachers. & .68 \\
\hline \multicolumn{3}{|c|}{ Group competence } \\
\hline$* \mathrm{GCM}$ & Teachers are confident they can motivate students. & .63 \\
\hline$* \mathrm{GCH}$ & Teachers in my school have what it takes to get the children to learn. & .79 \\
\hline$* \mathrm{GCB}$ & Teachers in my school really believe every child can learn. & .87 \\
\hline$* \mathrm{GCD}$ & Teachers in my school are able to get through to difficult students. & .83 \\
\hline *GCA & $\begin{array}{l}\text { If a child doesn't learn something the first time, teachers here will try } \\
\text { another way. }\end{array}$ & .85 \\
\hline
\end{tabular}

Note. *Items from the original Collective Efficacy Scale (Goddard, Hoy, Woolfolk Hoy, 2000).

Items aligned with either task analysis or group competence. The number of factors (two) divided by the number of indicators (four task analysis and five group competence items) was .22, adhering to suggested guidelines from Mueller and Hancock (2010) and Hakstian, Rogers, and Cattell (1982). The three task analysis items (Table 4.1) chosen from the TWC survey for the current study were statements about parent support ("Parents/guardians support teachers, contributing to their success with students"), a safe working environment ("The faculty work in a school environment that is safe"), and supportive school leadership ("The school leadership consistently supports teachers"). The TWC parent item chosen for the current study was somewhat similar to the collective efficacy long scale item, "Homelife provides so many advantages the 
students here are bound to learn." Likewise, the TWC item selected about a safe school environment was also similar to the Goddard and colleagues item (2000) "Learning is more difficult at this school because students are worried about their safety."

The TWC item "The school leadership consistently supports teachers," however, had no similarity to other items on the original collective efficacy long form (Goddard, Hoy, \& Woolfolk Hoy, 2000). I chose the item because it served as a contemporary example of task analysis. The power of school leadership has been a frequent topic in the literature in the past two decades, and it has an important influence on classroom teaching (see Hargreaves \& Fullan, 2012; Odden, 2011). In the end, EFA fit indices indicated that including the item was an asset to the scale, and the item was retained.

\section{Distinct Constructs}

The data support the first hypothesis that collective efficacy is comprised of two distinct constructs, group competence and task analysis. A CFA run with the Mplus default oblique geomin rotation for the second half of the sample $(n=194)$ verified the viability of the EFA two-factor solution. I set variances for task analysis and group competence to 1.00. As expected, fit indices for the CFA two-factor model were less desirable than indices for the EFA (Table 3.1) due to the more stringent requirements of a confirmatory factor analysis. However, adequate fit statistics for the two-factor model provided discriminant validity $(\mathrm{CFI}=.92, \mathrm{TLI}=.88, \mathrm{RMSEA}=.07[90 \%$ C.I. $=.04-$ $.10]$, SRMR $=.08)$. Factor loadings ranged from .595 to $.873(p<.001$, two-tailed $)$ (Figure 7). Task analysis and group competence correlated at $r=.406(p<.01$, twotailed). Scale reliability for the four task analysis items was $\alpha=.75$; for the five group competence items, $\alpha=.89$; for all nine items, $\alpha=.84$. 


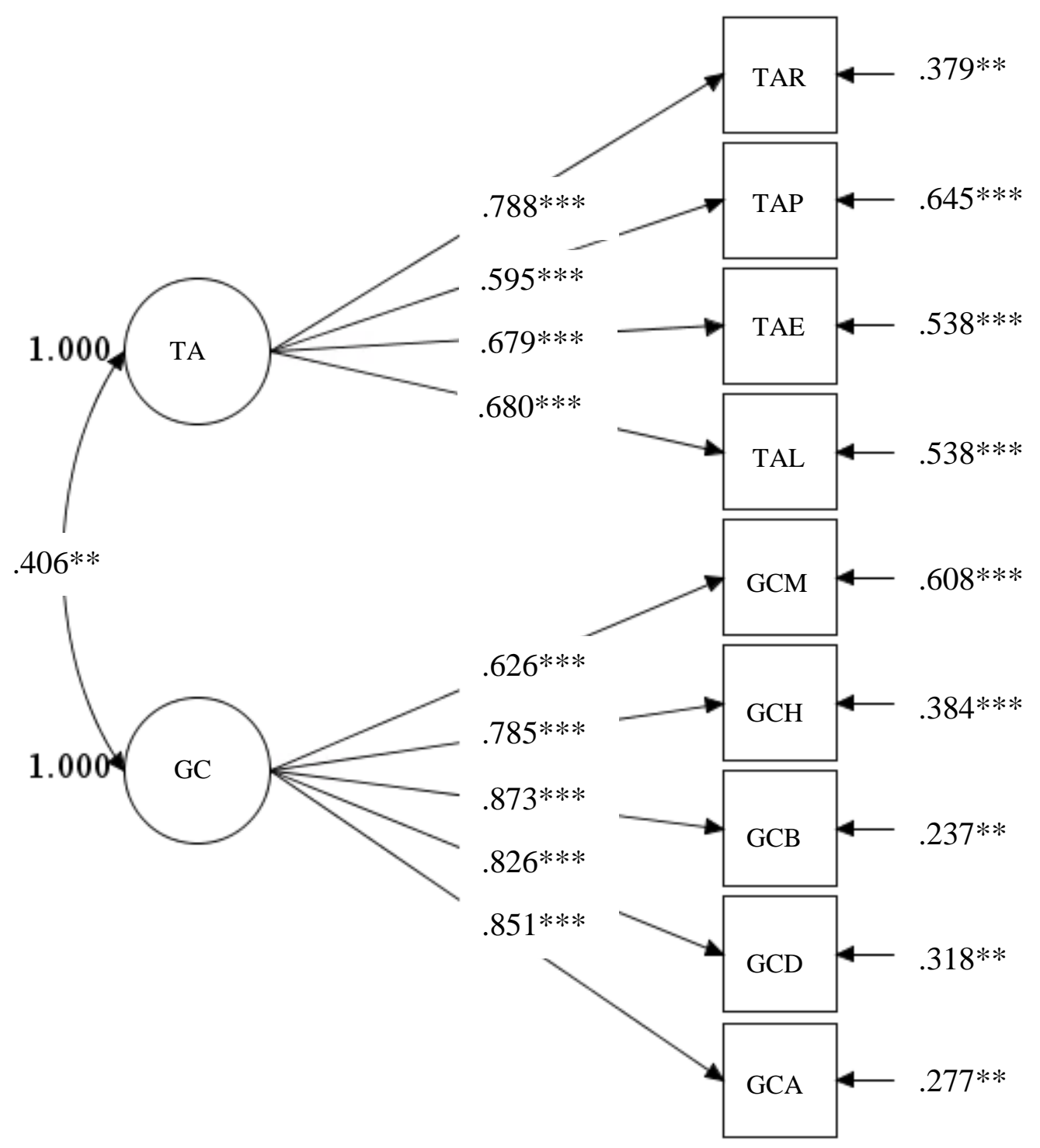

Figure 7. Confirmatory factor analysis loadings for the task analysis and group competence factors of collective efficacy theory.

Note. $* * p<.01, * * * p<.001$.

\section{Description of Collective Efficacy Perceptions}

To understand more about the perceptions of fourth- and fifth-grade teachers in this broad sample, the second research question of the study required the computation of 
measures of central tendency. A paired samples t-test using listwise deletion indicated a statistically significant difference between composite scores for task analysis and group competence. On average, teachers agreed less often with statements about obstacles or supports faced by their colleagues when educating students $(M=2.71, S D=.62)$ and agreed more often with statements about the competence of their teaching teammates $(M$ $=3.23, S D=.49), t(102)=-8.70, p<0.00$ at $\alpha=.05$, two-tailed, $r=0.41$. For this sample, standard deviation values suggest that teachers provided similar responses to group competence items more often than for task analysis. In other words, teachers were more likely to agree with each other that their colleagues taught well and less likely to agree about whether external factors posed as obstacles or supports to the team's task of teaching.

Tables 5.1 and 5.2 show additional descriptive statistics and correlations for group competence and task analysis. Both collective efficacy constructs positively correlated with observed Classroom Organization. Group competence also significantly correlated with the Emotional Support domain. Task analysis negatively correlated with the Negative Climate dimension of the Emotional Support domain. Group competence had similar significant correlations with Instructional Dialogue dimension of the Instructional Support domain. The absolute value of all significant correlations between collective efficacy constructs and CLASS dimensions ranged from $r=.15$ to $r=.20$. 
Table 5.1

Correlations and descriptive statistics for collective efficacy constructs, CLASS dimensions, and domainsS

\begin{tabular}{|c|c|c|c|c|c|c|c|c|c|c|c|c|c|}
\hline & 1 & 2 & 3 & 4 & 5 & 6 & 7 & 8 & 9 & 10 & 11 & 12 & 13 \\
\hline \multicolumn{14}{|l|}{ Constructs and CLASS dimensions } \\
\hline \multicolumn{14}{|l|}{ Items } \\
\hline 1. Task Analysis & - & & & & & & & & & & & & \\
\hline 2. Group Competence & $.37 * *$ & - & & & & & & & & & & & \\
\hline \multicolumn{14}{|l|}{ Dimensions } \\
\hline 3. Positive Climate & .06 & $.18^{*}$ & - & & & & & & & & & & \\
\hline 4. Negative Climate & $-.20 * *$ & $-.16^{*}$ & $-.49 * *$ & - & & & & & & & & & \\
\hline $\begin{array}{l}\text { 5. Teacher Sensitivity } \\
\text { 6. Regard for Student }\end{array}$ & .03 & .14 & $.83^{* *}$ & $-.44 * *$ & - & & & & & & & & \\
\hline Perspectives & -.03 & .11 & $.70 * *$ & $-.26 * *$ & $.66^{* *}$ & - & & & & & & & \\
\hline 7. Behavior Management & $.15^{* *}$ & .11 & $.44 * *$ & $-.74 * *$ & $.44 * *$ & $.24 * *$ & - & & & & & & \\
\hline $\begin{array}{l}\text { 8. Productivity } \\
\text { 9. Instructional Learning }\end{array}$ & $.15^{* *}$ & .15 & $.44^{* *}$ & $-.56^{* *}$ & $.48 * *$ & $.29 * *$ & $.75^{* *}$ & - & & & & & \\
\hline Formats & .06 & $.20^{*}$ & $.69 * *$ & $-.41 * *$ & $.71 * *$ & $.62 * *$ & $.47 * *$ & $.50 * *$ & - & & & & \\
\hline $\begin{array}{l}\text { 10. Content Understanding } \\
\text { 11. Analysis \& Problem }\end{array}$ & .03 & .07 & $.62 * *$ & $-.37 * *$ & $.65^{* *}$ & $.56^{* *}$ & $.42 * *$ & $.48^{* *}$ & $.77 * *$ & - & & & \\
\hline Solving & -.02 & .08 & $.60^{* *}$ & $-.32 * *$ & $.62 * *$ & $.67^{* *}$ & $.36^{* *}$ & $.37 * *$ & $.59^{* *}$ & $.66^{* *}$ & - & & \\
\hline 12. Quality of Feedback & .00 & .10 & $.76^{* *}$ & $-.38 * *$ & $.77^{* *}$ & $.66^{* *}$ & $.36^{* *}$ & $.40^{* *}$ & $.66^{* *}$ & $.72 * *$ & $.76^{* *}$ & - & \\
\hline 13. Instructional Dialogue & .04 & $.17^{*}$ & $.71 * *$ & $-.32 * *$ & $.72 * *$ & $.75^{* *}$ & $.31 * *$ & $.39 * *$ & $.68 * *$ & $.72 * *$ & $.77 * *$ & $.85^{* *}$ & - \\
\hline$N$ & 392 & 103 & 392 & 392 & 392 & 392 & 392 & 392 & 392 & 392 & 392 & 392 & 392 \\
\hline$M$ & 2.36 & 3.13 & 4.75 & 1.29 & 4.30 & 3.39 & 5.95 & 5.87 & 4.45 & 4.12 & 2.87 & 3.86 & 3.63 \\
\hline$S D$ & .59 & .67 & .56 & .30 & .48 & .53 & .52 & .39 & .44 & .45 & .53 & .51 & .53 \\
\hline Min & 0.00 & 1.00 & 3.00 & 1.00 & 2.88 & 2.13 & 2.88 & 3.88 & 3.00 & 2.88 & 1.67 & 2.60 & 2.50 \\
\hline Max & 4.00 & 4.00 & 6.50 & 3.25 & 6.50 & 5.00 & 6.78 & 6.75 & 6.50 & 6.50 & 4.20 & 5.25 & 5.50 \\
\hline
\end{tabular}

Note. $* p<.05, * * p<.01$. Table continued on following page. 
Table 5.2

Correlations and descriptive statistics for collective efficacy constructs, CLASS dimensions, and domains (continued)

\begin{tabular}{|c|c|c|c|c|c|}
\hline & 1 & 2 & 3 & 4 & 5 \\
\hline \multicolumn{6}{|l|}{ Predictor and outcome variables } \\
\hline \multicolumn{6}{|l|}{ Predictors } \\
\hline 1. Task Analysis & - & & & & \\
\hline 2. Group Competence & $.37 * *$ & - & & & \\
\hline \multicolumn{6}{|c|}{ Teacher-Student Interaction Quality } \\
\hline 3. Emotional Support & .06 & $.18^{*}$ & - & & \\
\hline 4. Classroom Organization & $.14^{* *}$ & $.18^{*}$ & $.52 * *$ & - & \\
\hline 5. Instructional Support & .02 & .12 & $.81^{* *}$ & $.62 * *$ & - \\
\hline$N$ & 392 & 103 & 392 & 392 & 392 \\
\hline$M$ & 2.36 & 3.13 & 3.43 & 5.42 & 3.62 \\
\hline$S D$ & .59 & .67 & .33 & .38 & .44 \\
\hline Min & 0.00 & 1.00 & 2.61 & 3.25 & 2.50 \\
\hline Max & 4.00 & 4.00 & 5.00 & 6.18 & 5.00 \\
\hline
\end{tabular}

Note. $* p<.05, * * p<.01$. Table continued from the previous page.

\section{Collective Efficacy and Teacher-Student Interactions}

To test RQ3, whether the group competence and task analysis constructs significantly relate to the three domains of teacher-student interaction quality, I executed an overidentified structural regression model in which all three domains were regressed on both constructs. Task analysis was regressed on group competence as a first step toward creating a potential mediation model. The measurement models for group competence and task analysis replicated the findings for RQ1 and are included in the full model (Appendix C). Domain composites for Emotional Support, Classroom 
Organization, and Instructional Support were used instead of including their respective dimensions as indicators in the model due to parameter constraints.

Figure 8 illustrates the structural model, while estimates, errors, and fit indices are shown in Table 6.1. We see a small, significant positive relation of group competence perceptions with the emotional support provided to students in the classroom $(\beta=.29, p<$ .05). The model also shows a moderate direct relation of group competence with task analysis $(\beta=.50, p<.001)$, similar to the results from analyses executed for RQ1. Group competence did not significantly relate to Classroom Organization or Instructional Support. Relations between task analysis and each of the three domains of teacherstudent interaction quality were also nonsignificant.

Hypothesis $3 \mathrm{~b}$ proposed a mediation model in which task analysis mediated the direct effect of group competence with each of the three teacher-student interaction quality domains. Therefore, I conducted mediation analyses with bootstrapping to test hypothesis H3b (Rucker, Preacher, Tormala, \& Petty, 2011). The results of analyses shown in Table 6.1 indicated no significant indirect effects for any of the three models, suggesting that task analysis did not mediate the effect of group competence with teacher-student interaction quality in the classroom. 


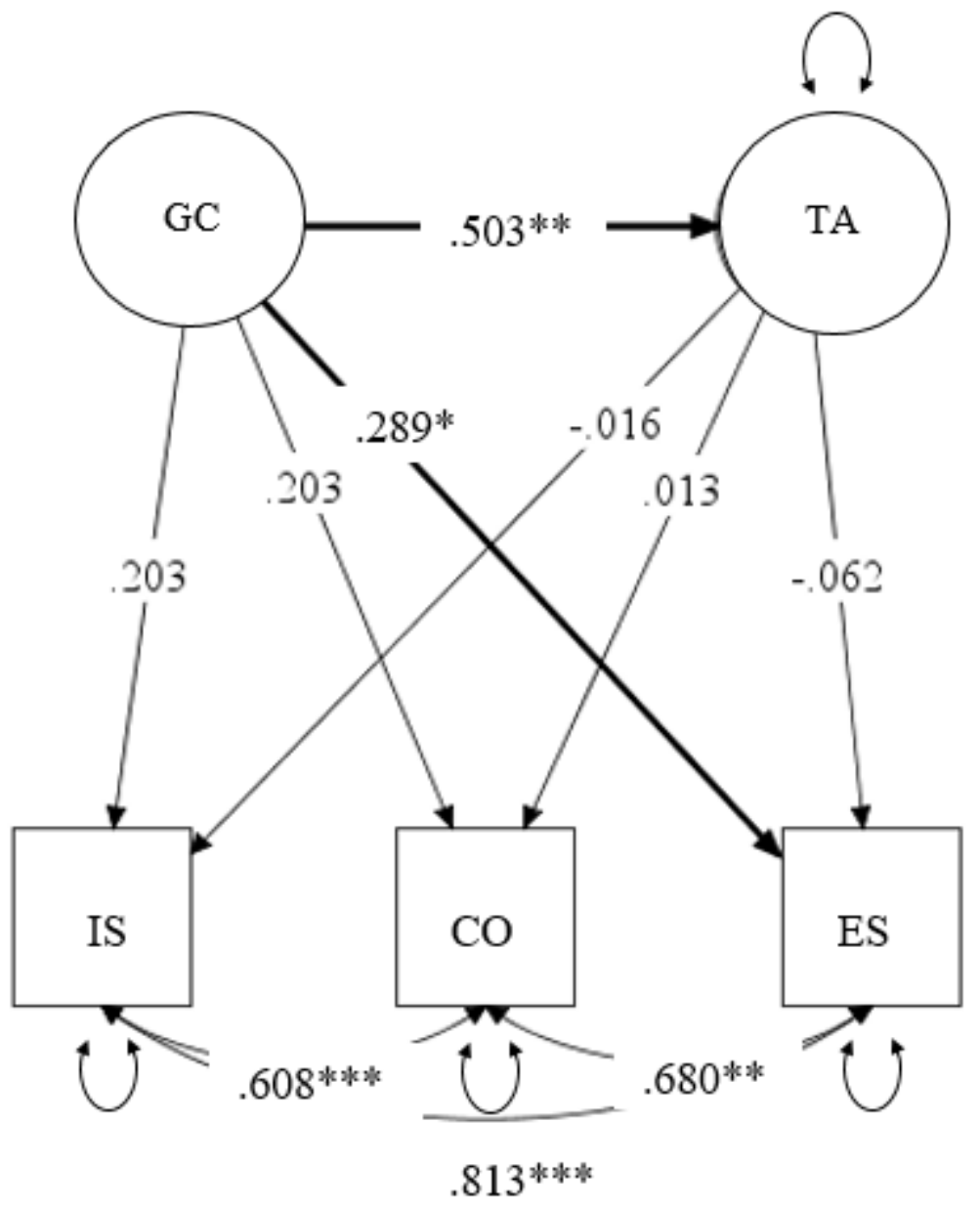

Figure 8. Structural model with group competence (GC) directly relating to task analysis (TA) and the Emotional Support (ES) domain of teacher-student interaction quality. Ovals represent latent variables. Rectangles represent observed variables. Bold lines indicate significance. $\mathrm{IS}=$ Instructional Support domain; $\mathrm{CO}=$ Classroom Organization domain; all other path coefficients and fit statistics are shown in Table 6.1. See Appendix $\mathrm{C}$ for the full model.

Note. $* p<.05, * * * p<.001$ 
Table 6.1

Standardized parameter estimates for path coefficients and fit indices for structural models

\begin{tabular}{|c|c|c|}
\hline & $\begin{array}{l}\text { Direct Effects } \\
\text { Model } \\
\text { Estimate (S.E.) }\end{array}$ & $\begin{array}{l}\text { Mediation } \\
\text { Model } \\
\text { Estimate } \\
\text { (S.E.) } \\
\end{array}$ \\
\hline \multicolumn{3}{|l|}{ Path coefficients (Direct effects) } \\
\hline Group competence $\rightarrow$ Task analysis & $.50(.12)^{* * *}$ & $.50(.12) * * *$ \\
\hline Group competence $\rightarrow$ Emotional support & $.29(.15)^{*}$ & $.29(.15)^{*}$ \\
\hline Group competence $\rightarrow$ Classroom organization & $.20(.13)$ & $.20(.13)$ \\
\hline Group competence $\rightarrow$ Instructional support & $.20(.16)$ & $.20(.16)$ \\
\hline Task analysis $\rightarrow$ Emotional support & $-.06(.12)$ & $-.06(.12)$ \\
\hline Task analysis $\rightarrow$ Classroom organization & $.01(.10)$ & $.01(.10)$ \\
\hline Task analysis $\rightarrow$ Instructional support & $-.02(.12)$ & $-.02(.12)$ \\
\hline \multicolumn{3}{|l|}{ Standardized direct, indirect, and total effects } \\
\hline $\begin{array}{l}\text { (Direct) Group competence } \rightarrow \text { Emotional support } \\
\text { (Indirect) Group competence } \rightarrow \text { Task Analysis }\end{array}$ & $.29(.15)^{*}$ & $.29(.15)^{*}$ \\
\hline$\rightarrow$ Emotional support & - & $-.03(.07)$ \\
\hline $\begin{array}{l}\text { (Total) Group competence } \rightarrow \text { Emotional support } \\
\text { (Direct) Group competence } \rightarrow \text { Classroom }\end{array}$ & $00(12)$ & $.26(.10)^{*}$ \\
\hline $\begin{array}{l}\text { organization } \\
\text { (Indirect) Group competence } \rightarrow \text { Task Analysis }\end{array}$ & $.20(.13)$ & $.20(.13)$ \\
\hline $\begin{array}{l}\rightarrow \text { Classroom organization } \\
\text { (Total) Group competence } \rightarrow \text { Classroom }\end{array}$ & - & $.01(.05)$ \\
\hline $\begin{array}{l}\text { organization } \\
\text { (Direct) Groun competence } \rightarrow \text { Instructional }\end{array}$ & - & $.21(.10)^{*}$ \\
\hline $\begin{array}{l}\text { support } \\
\text { (Indirect) Group competence } \rightarrow \text { Task Analysis }\end{array}$ & $.20(.16)$ & $.20(.16)$ \\
\hline$\rightarrow$ Instructional support & - & $-.01(.07)$ \\
\hline (Total) Group competence $\rightarrow$ Instructional support & - & $.20(.10)$ \\
\hline \multicolumn{3}{|l|}{ Model fit statistics } \\
\hline AIC & 3758.43 & 3758.43 \\
\hline CFI & .96 & .96 \\
\hline TLI & .95 & .95 \\
\hline \multicolumn{3}{|l|}{ RMSEA } \\
\hline Estimate & .05 & 0.05 \\
\hline $90 \%$ C.I. & $.03-.07$ & $.03-.07$ \\
\hline Probability RMSEA $<=.05$ & .51 & .51 \\
\hline \multicolumn{3}{|l|}{ 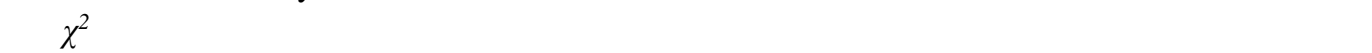 } \\
\hline Estimate & 91.91 & 91.91 \\
\hline$d f$ & 47 & 47 \\
\hline$p$-value & $<0.001$ & $<0.001$ \\
\hline
\end{tabular}

Note. $* p<.05, * * p<.01, * * * p<.001$ 


\section{Summary}

In this chapter, I reported the results for the three questions. First, I confirmed the distinction of group competence and task analysis as separate constructs through the use of exploratory and confirmatory factor analyses. Then, I reported descriptive statistics and bivariate correlations to illustrate the nature of task analysis and group competence item responses in a large national sample of teachers. Finally, I reported the results from a structural regression model investigating whether group competence and task analysis had direct effects on teacher-student interactions in the classroom. Findings showed that group competence had a small, significant effect on the Emotional Support domain. In the next chapter, I discuss these findings in the context of our current understanding of collective efficacy, acknowledge limitations present and propose steps for future research. 


\section{CHAPTER FIVE}

\section{DISCUSSION}

Access to this unique dataset has provided an unprecedented opportunity to investigate both the theoretical aspects and practical implications of collective efficacy. In this chapter, I discuss study results and why it matters that we think about collective efficacy as having two distinct components. I also speculate as to why teachers in this broad sample agreed with statements about their colleagues' abilities (group competence) and agreed less often with statements about supports and obstacles found in their daily working environments (task analysis). In addition, I unpack why positive teacher perceptions of their teaching team may help teachers provide emotional support to their students. The findings extend our knowledge of collective efficacy in important ways. I conclude with implications of the results and the potential distal benefits waiting for stakeholders in education.

\section{Distinct Constructs}

The first finding from the present study has significant implications for the future of collective efficacy theory. Factor analysis results confirmed a two-factor structure for collective efficacy, separating group competence and task analysis as distinct constructs. This finding supports the hypothesis for RQ1, based on a study by McCoach and Colbert (2010), while contradicting the work of Goddard, Hoy, and Woolfolk Hoy (2000). Reasons for the difference in conclusions drawn can be explained by revisiting Collective 
Teacher Efficacy Theory, the choice of analytical methods used by Goddard, Hoy, and Woolfolk Hoy (2000), and the characteristics of teachers and students in these studies. Interpretation of theory drove the choice of methods for determining factor structure in this study, as well as the study by Goddard and colleagues (2000). I considered the ways in which a teacher develops perceptions of their colleagues' abilities (group competence), and the ways in which a teacher forms perceptions about the obstacles and supports facing the teaching team as they attempt to successfully educate students (task analysis). According to Collective Teacher Efficacy Theory (Goddard, Hoy, \& Woolfolk Hoy, 2000), sources of collective efficacy include mastery experience, vicarious experience, social persuasion, and functional or dysfunctional affective states. Teachers gain a sense of collective efficacy through participating in positive, successful group activities in which they receive supportive feedback from principals or colleagues while mastering experiences, or see others like them mastering experiences (Goddard, Hoy, \& Woolfolk Hoy, 2000). As challenges arise either in group training activities or day-to-day professional situations, a group's sense of collective efficacy is tested. Teacher groups will take on functional or dysfunctional affective states in response to these challenges. Teachers either rise to a challenge or engage in dysfunctional affective behaviors.

Depending upon the ways in which teachers cognitively and emotionally process their experiences as a group, they may, for example, frame challenges as goals for the group to accomplish and take stock in previous evidence of the group's capabilities. They may see their colleagues as being able to motivate students and get through to even the most difficult students by trying various approaches to instruction (see these items on the 
group competence scale). As another example, they may blame their difficulties on those external factors beyond the realm of group control, such as whether students come to school ready to learn or parents and school leaders support teachers (examples of items on the task analysis scale). This blame may rise from the teaching team's lack of knowledge regarding how to navigate challenging situations successfully. Regardless, the sources of collective efficacy, and how teachers process those sources, influence the development of group competence perceptions (an estimation of internal assets or liabilities within the group) and perceptions of the obstacles or supports experienced by the group in their efforts to educate students (an estimation of external assets or liabilities encountered by the group). The roots of developing group competence or task analysis perceptions may be the same, but they develop into two unique constructs. Recognizing this difference will assist those who later wish to shift either type of perception held by a group or groups of teachers.

Choice of analytical methods based on theoretical perspective is an important explanation for the differences in factor structure. While acknowledging the distinct natures of each construct, Goddard, Hoy, and Woolfolk Hoy (2000) viewed group competence and task analysis as theoretical components that "interacted" equally and merged to become collective efficacy. With this view, they created their original scale measure by operationalizing group competence and task analysis as equal and unified in one collective efficacy factor. Their choice of methods followed their theoretical perspective. Herein lies the source of our difference in determining factor structure. Goddard and colleagues conducted principal axis factoring (PAF) with orthogonal varimax rotation using full sample size and correlated the long form scale with previous 
measures to assess construct validity. The authors conducted PAF solely for the purpose of eliminating weak items to strengthen a unified one-factor scale. In essence, they eliminated the possibility that group competence and task analysis could be two potentially correlating factors; their use of orthogonal rotation would not allow for that.

However, current study results differ from the findings of Goddard and colleagues (2000) because I used exploratory analyses with oblique rotation to allow for the possibility of a one- or a two-factor structure. I then followed the standard procedure of conducting confirmatory analyses to verify adequate fit indices for a two-factor model. Goddard and colleagues (2000) conducted principal axis factor analyses with orthogonal rotation to develop a single-factor collective efficacy scale as a measure reflective of their new theory; I explored the potential for either a one- or two-factor outcome.

Sample characteristics may have also contributed to the difference in results. Most teachers in the original collective efficacy study were female, White, and over half held a graduate degree (R. Goddard, personal communication, June 9, 2016). We also know that Goddard and colleagues (2000) selected their sample of 457 teachers from 47 elementary schools in one large urban district in the Midwest.

Almost two-thirds of the teachers in the sample for the current study are White, one-third are Black, and the majority are female. Of those who responded to the item about education level, fewer teachers held 33\% held Master's degrees. The sample of 392 teachers worked in 105 schools across five districts located in the Mid-Atlantic, Southeast, Southwest, and Western regions of the United States. It is understandable that teacher responses from both studies would markedly differ based on greater 
heterogeneity of perspectives inherent to the current study. As a result, factor analysis results from both studies would also differ.

On the other hand, the McCoach and Colbert study (2010) had results concurring with a two-factor structure for collective efficacy, yet the sample for that investigation was more similar to the sample in the original collective efficacy study (Goddard, Hoy, \& Woolfolk Hoy, 2000) than the current sample. The majority of the 1077 teachers from 44 schools across one New England state in the McCoach and Colbert sample (2010) were White, female, and $85 \%$ held a graduate degree. The most pronounced differences existed between teacher race and level of education; fewer teachers in the current study were White, and less than half held a graduate degree. Despite differences in the teacher sample composition, both the McCoach and Colbert study (2010) and the present study drew the same conclusion based on the results of factor analyses.

However, over half of the students in the Goddard, Hoy, and Woolfolk Hoy (2000) study were Black and the majority of the students had free-or-reduced lunch status (FRL). FRL student percentages were both approximately $30 \%$ for the McCoach and Colbert (2010) study and the current study, with slightly over a third of the students identifying as belonging to a minority in both studies. Perhaps the difference in student populations also contributed to the perceptions of teachers responding to scale questions, thus influencing the outcome of factor analyses and the finding of a two-factor solution in the current study and the study carried out by McCoach and Colbert (2010).

\section{Description of Collective Efficacy Perceptions}

For my second hypothesis, I expected the broad sample of teachers from five different districts across four geographic United States regions would vary widely in their 
perceptions of group competence and task analysis. Identifying the degree to which variation exists and understanding sources of variation are key steps for changing educational outcomes (Bryk, 2015). Variation tends to be the norm in education. This is not surprising given the amount of state and local control in educational decision-making.

Group competence and variation. Findings showed that teacher responses to group competence items were more consistent across the sample than teacher responses to task analysis items. Why might there be less variation around group competence? Perhaps larger groups of teachers in the sample share the same ideas about what it means for a teacher to be competent. After all, states determine teacher certification training and licensure requirements, instilling common ideas about the criteria for instructional competence. It is likely that large groups of the teachers in the sample were trained in the same state with their colleagues.

In addition, local divisions govern the degree to which teachers experience professional development, as well as the manner in which teachers interact during training. Often these decisions are based on trends promoted by national educational organizations or recent research literature. For example, collaborative work among teachers has become the norm in both professional development and day-to-day planning (Goddard, Goddard, \& Tschannen-Moran, 2007; Hargreaves \& Fullan, 2012; Moolenear, 2012; Odden, 2011). Teachers are emerging from the isolation of their classrooms as a matter of course, and familiarity with colleagues broadens a teacher's knowledge of other teachers' strengths and weaknesses. Work groups are often tasked with specific goals in mind. For example, grade-level teachers create common units and assessments, then together monitor student progress toward learning goals. There is an element of 
accountability in these interactions that may foster either favorable (or unfavorable) views of colleague competence. In the case of the present study, teachers in the sample generally agreed that their fellow teachers have what it takes to educate children, they believe that every child can learn, they can get through to difficult students and motivate them, and they're willing to teach in a variety of ways to help students.

Task analysis and variation. On the other hand, teachers across the sample were less consistent in their responses to task analysis items. Overall, teachers in the sample did not completely agree that their students came ready for school, that parents and school leaders were supportive, or that they were working in a safe environment. However, the variety of responses to these items were spread more widely than the group competence responses. Why might this be the case?

It is possible that variation in collective efficacy perceptions is tied to geography. Consider the ways in which conditions beyond the control of teachers differ from school to school, even within one district (Duncan \& Murnane, 2011). Schools in neighborhoods with affluent families may have parents who are more vocal about school leadership and the conditions of facilities, sometimes donating additional funds or materials through parent-teacher organizations. The availability for school funding is also often tied to the socioeconomic status of the community. Taxes levied on affluent communities will generate greater funding for local schools than the funding generated in poorer communities. Therefore, students in wealthier schools are more likely to benefit from higher-quality school facilities when compared with facilities in schools with more disadvantaged populations. 
Therein lies a potential source of wider variation among responses to task analysis: teachers in the sample are less likely to encounter the same conditions at their school when compared to a teacher at another school (Duncan \& Murnane, 2011). The lack of agreement with task analysis statements (indicating the students are not ready, parents show low support, the school environment is unsafe, and school leadership is not supportive) may be tied to the economic downturn in the United States beginning in 2008; repercussions from the financial struggles of families affected both adult and child development (Edin \& Kissane, 2010), and most states are not funding schools at levels seen before the recession (Leachman \& Mai, 2014).

To improve group competence and task analysis perceptions, researchers, policy makers, program developers, and administrators must understand not only the mean level of teacher perceptions but also the sources of variation around those means. Teachers in the McCoach and Colbert study (2010) "somewhat agreed" with the task analysis statements and "agreed" with group competence statements. However, like the present study, there was more variation across responses to task analysis items than across responses to group competence items. Goddard, Hoy, and Woolfolk Hoy (2000) did not report individual means and standard deviations for group competence and task analysis. The similarities between results for the means and variations in this study and the McCoach and Colbert study (2010) may help the educational community attend to possible consistencies in degrees of variation and sources of variation for group competence and task analysis in other studies, as well. Future program developers may use this knowledge as a beginning point for investigating sources of variation in the effectiveness of their program. They may target just the lowest groups as they create 
interventions (Bryk, 2015) designed to improve teacher perceptions of group competence and task analysis.

Maybe by nature, group competence will consistently have less variation than task analysis. Studies in social psychology long ago recognized that people generally prefer not to exist in a state of contention with others in a group, which causes a state of social tension within the individual (Festinger, 1954; Festinger, Schachter, \& Back, 1950). These situations challenge individual perceptions of self-esteem (called cognitive dissonance) (Festinger, 1957). A person attempts to reduce this dissonance by aligning their behavior with others' behavior, adjusting the initial perceptions creating dissonance, or developing new rationales for justifying their behavior. It is believable that groups of teachers would share consistently favorable group competence perceptions when we consider that people prefer to avoid contention with their colleagues. In the event that problems arise in the school or the classroom to threaten group and individual perceptions of self-esteem, it is also conceivable that teachers would blame other factors external to the group and develop negative task analysis perceptions.

Correlations with task analysis. Bivariate correlations for the collective efficacy constructs and CLASS dimensions were small $(r \leq .2)$. However, a pattern found in the dimension correlations with task analysis is worth noting. Teachers with higher task analysis scores (agreeing with item statements) tended to have classrooms with lower Negative Climate, higher Behavior Management, and higher Productivity scores. In other words, teachers were more likely to successfully engage in self-regulatory behaviors while interacting with students in the classroom when these teachers perceived that students were coming to school ready to learn, parents and principals were supportive, 
and their school environments were safe. It is possible that positive views of task analysis support teachers' self-regulation in the classroom. For instance, a teacher who feels safe in the school environment may have more emotional capacity to deal with challenging situations and may be less likely to criticize or speak harshly to her students. Teachers who feel that their students come to school ready to learn may be working with children who show more self-control in the classroom. In turn, it may be easier for teachers to facilitate productivity in the classroom and use proactive as opposed to reactive approaches to classroom management.

However, we have no indication of directionality in the bivariate correlations. It is possible that teachers with lower CLASS dimension scores for Negative Climate, higher scores for Behavior Management, and higher scores for Productivity also agree with task analysis item statements. For example, with a well-ordered and productive classroom in which the teacher is not treating students harshly or unfairly, teachers are more likely to encounter parents or school leaders who might approve of and support the ways in which the teacher interacts with students.

Similar patterns follow when teachers agree less often with task analysis item statements and have higher Negative Climate dimension scores, lower Behavior Management scores, and lower Productivity scores. Teachers serving areas with lower income levels often work with less than adequate instructional resources (The Equity and Excellence Commission, 2013). In addition, building positive ties with families can involve tremendous effort and struggle (Adams \& Christenson, 2000; Bryk \& Schneider, 2002; Bryk, Sebring, Allensworth, Luppescu, \& Easton, 2010; Hughes \& Kwok, 2007). Many teachers must also strive to keep students focused and engaged, providing 
foundational support for students' self-regulation, motivation, and persistence; not all students come to school enthusiastic about learning (Zimmerman, 2008).

Perhaps holding a more negative perception of task analysis leaves a teacher feeling unable to control her classroom environment, leading to a lower capacity for selfregulation. To her, students may seem like they are neither emotionally nor cognitively ready for school because they fail to work diligently in her classroom. This also may lead to the less favorable, negatively reactive treatment of students in an unproductive classroom atmosphere (Feldon, 2007; Rodriguez \& Fitzpatrick, 2014).

Correlations in this pattern are small, meaning that other factors likely influence the association between task analysis and the three CLASS dimensions. However, as I will repeat later, this is a small but important piece. Additional studies may find the same association between task analysis perceptions and teacher self-regulation in the classroom, perhaps to an even greater extent. In that event, subsequent discussions about how to foster positive task analysis perceptions in teachers should become a priority.

\section{Collective Efficacy and Teacher-Student Interactions}

The third hypothesis predicted that a teacher's perception of group competence (the abilities of the teaching team) would relate to all three areas of observed classroom instruction. Specifically, I expected the strongest relationships to exist for group competence with Emotional Support, as well as group competence with Instructional Support. Group competence had a small, significant association with the provision of emotional support to students in the classroom, but associations between group competence and Classroom Organization, as well as group competence and Instructional Support, failed to emerge. 
Looking closely at the bivariate correlations provides additional information. Among the dimensions of Emotional Support, group competence correlated positively with Positive Climate and negatively with Negative Climate. In other words, a teacher's perception of their teaching team's capabilities related positively with the teacher's ability to create substantive emotional connections with students by demonstrating warmth and respect during verbal and non-verbal interactions. However, there were no correlations between group competence and Teacher Sensitivity or Regard for Student Perspectives. Said another way, teacher perceptions of group competence had no association with the teacher's ability to respond in a timely and appropriate manner to student needs or the teacher's ability to understand student interests and ideas in an effort to foster autonomy and responsibility for the student's own learning. Instead, group competence was associated with the most emotional aspects of Emotional Support.

Why would perceptions of group competence be associated with emotional support? The direction of the effect is unclear, but perhaps a teacher who regularly seeks out advice or works together with colleagues to improve emotional support provided during teacher-student interactions will also gain more knowledge about the professional competence of their teammates. A staff development initiative, such as training for implementation of a school social and emotional learning program, might simultaneously influence perceptions of colleague capabilities while changing teacher approaches to providing emotional support for students. On the other hand, could it be possible that characteristics inherent to a teacher, manifesting as emotionally supportive (or unsupportive) behaviors in the classroom, might also influence a teacher's perception of group competence? The lack of significant associations between group competence and 
Classroom Organization or group competence and Instructional Support might support this idea. Teacher proficiencies in Classroom Organization and Instructional Support are learned skills and are not natural characteristics; strong interpersonal skills are more likely to be innate human characteristics. For example, a teacher who warmly solicits the opinions of colleagues, giving others a chance to help another teammate, might also be predisposed to showing the same positive, encouraging behaviors with students in their classroom. The natural propensity for a teacher to see life in a positive or negative light would likely extend to their perceptions of student and colleague capabilities.

The importance of the association between the way in which a teacher perceives the capabilities of his or her teaching team and emotional support provided in the classroom should not be overlooked, despite the small size of the effect. We can outline the mechanics of establishing a positive climate in the classroom and sensitively attending to student perspectives; many teachers participate in this type of training as schools implement social and emotional learning programs (e.g. Reyes, Brackett, Rier, Elbertson, \& Salovey, 2012; Rimm-Kaufman et al., 2014). Nevertheless, how well and for how long could a teacher provide positive emotional support to his or her students if the teacher did not view the abilities of their teammates favorably? Could the benefits of instructing teachers in the mechanics of providing emotional support to students even be sustainable if the teacher held negative perceptions of group competence? Teachers operate within a larger school ecological system. The association between teacher perceptions of group competence and emotional support provided in a classroom may only be a piece of a larger puzzle. 
In addition to the hypothesized association of group competence with each of the three domains of teaching, I posited that a teacher's task analysis perceptions would mediate the effect that group competence had on teacher-student interactions in the classroom. Findings showed that task analysis had no direct or indirect association with the observed domains of teacher-student interaction quality. For the sample of teachers in the current study, an individual teacher's perception of the challenges and supports to teaching faced by all of the instructional staff at each school was not strong enough to be noticeably related to observed teacher-student interactions in the classroom. The results might have been very different if the study included middle or high school teachers. Elementary schools have smaller communities of students and stakeholders. It is likely more feasible for elementary teachers to develop positive relationships with principals, students, and parents. In the process, elementary teachers may develop the perception that members of the school community are, at a minimum, not obstacles to the task of teaching.

It is also important to note that task analysis and group competence were moderately related with $25 \%$ percent of the variance overlapping. It is worthwhile to consider the reason for this overlap. Goddard, Hoy, \& Woolfolk Hoy (2000) suggested that task analysis informs perceptions of group competence, and vice versa. Perhaps this is true in certain situations, but not others. For example, imagine a group of teachers at a school who are told they will be teaching students with autism in the upcoming year. As they form task analysis perceptions, they might consider their own lack of experience with this population, doubt their own instructional capabilities and form negative perceptions of group competence (W. Hoy, personal communication, August 21, 2015). 
However, a team of teachers with a successful record of assisting students with autism might have positive perceptions of their own group competence and, in turn, have no doubts about the task of teaching more students with autism in the future. We then wonder, when does group competence inform task analysis? When does task analysis inform group competence? Are there situations when the relationship between the two constructs are more complex?

Another approach would be to understand how group competence and task analysis vary across schools. When teachers at different sites serve student populations with similar within-school characteristics, are there similarities in group competence and task analysis perceptions across schools? As previously discussed, an investigation of the sources of group competence and task analysis perceptions would further our understanding of how to potentially shift these perceptions among teachers. Such an investigation may uncover the reasons task analysis and group competence perceptions overlap, as well.

\section{Limitations}

The present study has a number of strengths as an exploration of collective efficacy theory and its relationship to the quality of teacher-student interactions in the classroom. However, challenges come with conducting a study using an existing dataset. For the current investigation, the use of cross-sectional panel data from the first year of the MET study imposed four limitations.

First, sample size was limited to only fourth- and fifth-grade teachers in the MET study who responded to the TWC survey and participated in CLASS observations. Although the MET participants came from a broad sample of teachers, they were 
volunteers in the MET Project and the characteristics of the group are not nationally representative. Second, the use of panel data also limits our ability to understand the direction of factor associations. Although theory provided a sound justification for the proposed direction of effects, longitudinal data are needed to establish causal relationships.

Third, inter-rater reliability values for classroom observations were below desired levels of agreement. Under this circumstance, the likelihood of a Type II error increases (failing to claim the presence of a significant relation when one exists) (Zuckerman, Hodgins, Zuckerman, \& Rosenthal, 1993). However, Type I errors do not become more likely, so significant relationships found in this study are genuine. Low reliability may have obscured the detection of other significant relationships that may also exist. Future investigations should consult the Classroom Assessment Scoring System (CLASS): Upper Elementary Manual (Pianta, Hamre, \& Mintz, 2012) to ensure high levels of reliability during a study lasting more than a few months. Program developers recommend that observers become certified by attending a two-day CLASS Observation Training with follow-up coding sessions, and that observers maintain reliability by participating in double-coding as well as regularly-scheduled calibration meetings. By nature, maintaining coder reliability is a difficult undertaking for large-scale studies such as the MET Project.

Finally, the collective efficacy measure developed in the present study is theoretically sound, but it was created using items selected from the TWC survey. Therefore, similarities and differences exist between the measure developed in the current study and the original Collective Efficacy Scale long form (Goddard, Hoy, \& Woolfolk 
Hoy, 2000). For example, while six of the selected items were also items from the original Collective Efficacy Scale long form (Goddard, Hoy, \& Woolfolk Hoy, 2000), two selected items were only similar in content. The remaining TWC item was selected because I saw that it represented an important task analysis perception (support from school leadership) absent from the original collective efficacy measure. With the exception of the task analysis item regarding teachers working in a safe environment, task analysis statements primarily targeted relationships supporting or creating obstacles for the teaching team (student readiness, parent support, and support from school leadership). The range of possible items categorized as task analysis is quite broad, and factor analyses conducted in this study found cohesion in a scale with items mostly addressing team relationships with others.

Also, the original long form included both positively- and negatively-worded items; I included only positively-worded items in the measure for this study. In addition, the long form Likert scale employed the following response options: $1=$ Strongly Disagree, $2=$ Disagree, $3=$ Somewhat Disagree, $4=$ Somewhat Agree, $5=$ Agree, and 6 = Strongly Agree. As described previously, I used a 4-point Likert scale without choices for Somewhat Disagree or Somewhat Agree, and an additional response choice was provided for $5=$ I Don't Know. Comparisons between this study and other studies using the original Collective Efficacy Scale long form (Goddard, Hoy, \& Woolfolk Hoy, 2000) should be made with this in mind.

\section{Contributions and Future Research}

This study is the first to begin unpacking the black box situated between collective efficacy perceptions and student outcomes. Previous studies of collective 
efficacy contribute important information by demonstrating the association between teachers' perceptions of their working contexts and student achievement scores (Goddard, 2002; Goddard, Hoy, \& Woolfolk Hoy, 2000; Tschannen-Moran \& Barr, 2004). However, such work stops short of investigating the underlying mechanisms driving this connection. This dissertation contributes to the body of literature on collective efficacy by reaffirming the two-factor structure of collective efficacy and identifying the presence and absence of links between collective efficacy and teachers' interactions with students. This exploratory investigation has implications for the ways in which future investigators conceptualize and measure collective efficacy.

Confirmatory factor analysis results suggest that group competence and task analysis should be measured on separate scales. The group competence items described by Goddard and colleagues can be retained in future assessments (Goddard, Hoy, Woolfolk Hoy, 2000). However, times have changed, school culture has shifted and schools present teachers with new challenges. As a result, a review of task analysis items may be needed. We must ask, "What are the biggest challenges that classroom teachers today experience as they strive to educate students?" and "What are the most beneficial supports, as well as the most burdensome obstacles, that we face on our teaching team when educating our students?" The development of stronger scale measures would support research clarifying how task analysis and group competence perceptions operate in relation to one another. This will be a crucial step for revising collective efficacy theory.

The results from this study also suggest that task analysis perceptions relate to teacher self-regulation in the classroom, and group competence perceptions relate to the 
provision of emotional support to students. These relations are reminiscent of the necessary conditions for the prosocial classroom model described by Jennings and Greenberg (2009). The authors propose that high-quality teacher-student interactions in the classroom are only possible through caring for the well-being of teachers and supporting their social and emotional competence. Perhaps pursuing the work of Jennings and Greenberg (2009) and fostering a positive sense of well-being in teachers through self-regulation and the provision of environmental supports would improve task analysis and group competence perceptions in teachers.

Exploratory investigations such as this study serve as an important precursor to pursuing additional experimental work. New programs require research methods that permit exploration and the generation of new theory (Shavelson \& Towne, 2002). On the Institute of Education Sciences continuum of research study types, descriptive exploratory studies pave the way for development and innovation investigations, followed by evaluation studies, as well as assessment development and validation projects (Okagaki, Albro, \& Buckley, 2009). Descriptive exploratory studies, for example, might investigate associations between constructs and outcomes, or malleable processes that might shift during the implementation of a newly-developed intervention (Okagaki et al., 2009).

Thus, the potential for improving schools through the introduction of programs for developing more positive staff collective efficacy perceptions is impossible without understanding how these perceptions work in schools and classrooms. The present study moved this agenda forward by applying the two-factor model to answer whether and how the perceptions of an individual teacher, as part of a school teaching team, affect the 
observed quality of that teacher's interactions with students in the classroom. By looking inside classrooms, the results indicate that group competence may be one bridge between the collective efficacy perceptions of teachers and student academic outcomes.

An important next step in collective efficacy research would be to establish causality between the group competence and task analysis factors and educational outcomes. This requires conducting a longitudinal study, conceivably employing a crosslagged panel design. Longitudinal data could be used to examine whether perceptions of task analysis mediate, or moderate, the effects of group competence on educational outcomes, or vice versa. The results of such a study have the added benefit of informing collective efficacy theory and the development of future programs to alter teacher perceptions.

\section{Conclusion}

We study teachers to understand them as individuals with their own personal attributes interacting with their school contexts (Bandura, 1986). However, the unit of analysis for the current study was not just an individual teacher, nor was it groups of teachers melded into collective units; the unit of analysis was an individual teacher simultaneously operating in her respective roles as a member of a teaching team and as an autonomous authority in her own classroom. Teachers act as both. Their perceptions of relationships with colleagues, and their reactions to external factors influencing their working contexts, affect their choice of teaching behaviors in the classroom.

This is the heart of Collective Teacher Efficacy Theory (Goddard, Hoy, \& Woolfolk Hoy, 2000), a valuable contribution to the field of educational research that deserves additional refinement and investigation. Initial studies have been useful in 
linking collective efficacy (i.e., group perceptions of teachers in their working contexts) to student achievement scores (Goddard, 2002; Goddard, Hoy, \& Woolfolk Hoy, 2000; Tschannen-Moran \& Barr, 2004). With the present study, we have begun to unpack what is happening when a teacher carrying perceptions of collective efficacy, influenced by all of the ecological factors present in the school working context, interacts with the students in his or her classroom. However, this investigation is only a beginning. We still lack a complete understanding of how collective efficacy perceptions affect teacher behaviors in the classroom and how to alter those perceptions. Researchers may find that improving teacher perceptions of collective efficacy calls for a two-pronged approach. Perhaps while policy-makers and administrators help create healthy working contexts for teachers, simultaneously encouraging teachers to engage in self-care approaches could improve their psychological dispositions and collective efficacy perceptions. With this understanding, future investigations of collective efficacy have the potential to influence the ways in which program developers, policymakers, administrators, and teacher leaders pursue innovative approaches to school improvement. 


\section{REFERENCES}

Abry, T., Rimm-Kaufman, S. E., Larsen, R. A., \& Brewer, A. J. (2013). The influence of fidelity of implementation on teacher-student interaction quality in the context of a randomized controlled trial of the Responsive Classroom approach. Journal of School Psychology, 51(4), 437-453.

Adams, K. S., \& Christenson, S. L. (2000). Trust and the family-school relationship examination of parent-teacher differences in elementary and secondary grades. Journal of School Psychology, 38(5), 477-497.

Allen, J. P., Pianta, R. C., Gregory, A., Mikami, A. Y., \& Lun, J. (2011). An interactionbased approach to enhancing secondary school instruction and student achievement. Science, 333, 1034-1037.

Anderson, L., Everston, C., \& Brophy, J. (1979). An experimental study of effective teaching in first-grade reading groups. Elementary School Journal, 79, 193-223.

Angelle, P., \& Teague, G. (2014). Teacher leadership and collective efficacy: Teacher perceptions in three U. S. school districts. Journal of Educational Administration, $52(6), 738-753$.

Avant, T. S., Gazelle, H., \& Faldowski, R. (2011). Classroom emotional climate as a moderator of anxious solitary children's longitudinal risk for peer exclusion: A child x environment model. Developmental Psychology, 47, 1711-1727.

Bandalos, D. L. \& Finney, S. J. (2010). Factor analysis: Exploratory and confirmatory. In G. R. Hancock \& R. O. Mueller (Eds.) The reviewer's guide to quantitative methods in the social sciences (pp. 93-114). New York, NY: Routledge. 
Bandura, A. (1986). Social foundations of thought and action: A social cognitive theory. Englewood Cliffs, NJ: Prentice-Hall.

Bandura, A. (1993). Perceived self-efficacy in cognitive development and functioning. Educational Psychologist, 28, 117-148.

Bandura, A. (1997). Self-efficacy: The exercise of control. New York, NY: W. H. Freeman and Company.

Baron, R. M., \& Kenny, D. A. (1986). The moderator-mediator variable distinction in social psychological research: Conceptual, strategic, and statistical considerations. Journal of Personality and Social Psychology, 51, 1173-1182.

Bentler, P. M., \& Chou, C. (1987). Practical issues in structural modeling. Sociological Methods \& Research, 16, 78-117.

Bill \& Melinda Gates Foundation, Measures of Effective Teaching Project. (2010, September). Teachers' perceptions and the MET Project. Retrieved from MET Project website: http://www.metproject.org/downloads/Teacher_Perceptions_092110.pdf

Bill \& Melinda Gates Foundation, Measures of Effective Teaching Project. (2013a, January). Ensuring fair and reliable measures of effective teaching. Retrieved from MET Project website: http://www.metproject.org/downloads/MET_Ensuring_Fair_and_Reliable_Measu res_Practitioner_Brief.pdf

Bill and Melinda Gates Foundation. (2013b). Measures of Effective Teaching: 2 - Core Files, 2009-2011. ICPSR34414-v3. Ann Arbor, MI: Inter-university Consortium 
for Political and Social Research [distributor], 2013-09-23.

http://doi.org/10.3886/ICPSR34414.v3

Birch, S. H., \& Ladd, G. W. (1997). The teacher-child relationship and children's early school adjustment. Journal of School Psychology, 35, 61-79.

Bollen, K. A. (1989). A new incremental fit index for general structural equation models. Sociological Methods \& Research, 17, 303-316.

Bollen, K. A., \& Stine, R. R. (1992). Bootstrapping goodness-of-fit measures in structural equation models. Sociological Methods and Research, 21, 205-229.

Bowlby, J. (1982). Attachment and loss: Vol. 1. Attachment (2 ${ }^{\text {nd }}$ ed.). New York, NY: Basic Books.

Bronfenbrenner, U., \& Morris, P. A. (1998). The ecology of developmental processes. In W. Damon \& R. M. Lerner (Eds.), Handbook of child psychology: Vol. 1. Theoretical models of human development ( $5^{\text {th }}$ ed., pp. 993-1028). New York, NY: Wiley.

Brophy, J. (2006). Observational research on generic aspects of classroom teaching. In P. A. Alexander \& P. H. Winne (Eds.), Handbook of educational psychology $\left(2^{\text {nd }}\right.$ ed., pp. 755-777). New York: Routledge.

Brown, T. A. (2015). Confirmatory factor analysis for applied research ( $2^{\text {nd }}$ ed.). New York, NY: Guilford Press.

Bryk, A. S. (2015). 2014 AERA distinguished lecture: Accelerating how we learn to improve. Educational Researcher, 44, 467-477.

Bryk, A. S. \& Schneider, B. (2002). Trust in schools : A core resource for improvement. New York, NY: Russell Sage Foundation. 
Bryk, A. S., Sebring, P. B., Allensworth, E., Luppescu, S., \& Easton, J. Q. (2010).

Organizing schools for improvement: Lessons from Chicago. Chicago, IL: University of Chicago Press.

Burns, M. K., \& Symington, T. (2002). A meta-analysis of prereferral intervention teams: Student and systemic outcomes. Journal of School Psychology, 40(5), 437-447.

Coleman, J. S., Campbell, E. Q., Hobson, C. J., McPartland, F., Mood, A. M., Weinfeld, F. D., \& York, R. L. (1966). Equality of educational opportunity. Washington, DC: U.S. Government Printing Office.

Cohen, J. (1992). A power primer. Psychological Bulletin, 112, 155-159.

Connell, J. P., \& Wellborn, J. G. (1991). Competence, autonomy, and relatedness: A motivational analysis of self-system processes. In M. R. Gunnar \& L. A. Sroufe (Eds.), Self processes and development. The Minnesota symposia on child psychology (Vol. 23, pp. 43-77). Hillsdale, NJ: Erlbaum.

Davis, H. A. (2003). Conceptualizing the role and influence of student-teacher relationships on children's social and cognitive development. Educational Psychologist, 38(4), 207-234.

Domitrovich, C. E., Bradshaw, C. P., Poduska, J. M., Hoagwood, K., Buckley, J. A., Olin, S., Romanelli, L. H., Leaf, P. L., Greenberg, M. T., \& Iaongo, N. S. (2008). Maximizing the implementation quality of evidence-based preventive interventions in schools: A conceptual framework. Advances in School Mental Health Promotion, 1(3), 6-28.

DuFour, R. (2004). What is a "Professional Learning Community"? Educational Leadership, 61(8), 6-11. 
Duncan, G. J., \& Murnane, R. J. (2011). Whither opportunity? Rising inequality, schools, and childern's life chances. New York, NY: Russell Sage Foundation.

Durlak, J. A., Weissberg, R. P., Dymnicki, A. B., Taylor, R. D., \& Schellinger, K. B. (2011). The impact of enhancing students' social and emotional learning: A metaanalysis of school-based universal interventions. Child Development, 82(1), 405432.

Edin, K., \& Kissane, R. J. (2010. Poverty and the American family: A decade in review. Journal of Marriage and Family, 72, 460-479.

Enders, C. K. (2001). A primer on maximum likelihood algorithms available for use with missing data. Structural Equation Modeling, 8, 128-141.

Evans, R. (1996). The human side of change. San Francisco, CA: Jossey-Bass.

Feldon, D. F. (2007). Cognitive load and classroom teaching: The double-edged sword of automaticity. Educational Psychologist, 42(3), 127-137.

Ferguson, R. F., \& Hirsch, E. (2014). How working conditions predict teaching quality and student outcomes. In T. J. Kane, K. A. Kerr, \& R. C. Pianta (Eds.), Designing teacher evaluation systems: New guidance from the Measures of Effective Teaching Project (pp. 332-380). San Francisco, CA: Jossey-Bass.

Festinger, L. (1954). A theory of social comparison processes. Human Relations, 7, 114140.

Festinger, L. (1957). A theory of cognitive dissonance. Stanford, CA: Stanford.

Festinger, L., Schachter, S., \& Back, K. (1950). Social pressures in informal groups: A study of human factors in housing. New York, NY: Harper. 
Fives, H., \& Buehl, M. M. (2012). Spring cleaning for the "messy" construct of teachers' beliefs: What are they? Which have been examined? What can they tell us? In K. R. Harris, S. Graham, \& T. Urdan (Editors-in-Chief), APA educational psychology handbook: Vol. 2 (pp. 471-499). Washington, DC: American Psychological Association.

Fleiss, J. L. (1981). Statistical methods for rates and proportions ( $2^{\text {nd }}$ ed.). New York, NY: John Wiley \& Sons, Inc.

Furrer, C., \& Skinner, E. (2003). Sense of relatedness as a factor in children's academic engagement and performance. Journal of Educational Psychology, 95, 148-162.

Goddard, R. D. (2002). A theoretical and empirical analysis of the measurement of collective efficacy: The development of a short form. Educational and Psychological Measurement, 62(1), 97-110.

Goddard, R. D., \& Goddard, Y. L. (2001). A multilevel analysis of teacher and collective efficacy. Teaching and Teacher Education, 17, 807-818.

Goddard, R. D., Hoy, W. K., \& Woolfolk Hoy, A. (2000). Collective teacher efficacy: Its meaning, measure, and impact on student achievement. American Educational Research Journal, 37(2), 470-507.

Goddard, R. D., Hoy, W. K., \& Woolfolk Hoy, A. (2004). Collective efficacy beliefs: Theoretical developments, empirical evidence, and future directions. Educational Researcher, 33(3), 3-13.

Goddard, Y. L., Goddard, R. D., \& Tschannen-Moran, M. (2007). A theoretical and empirical investigation of teacher collaboration for school improvement and 
student achievement in public elementary schools. Teachers College Record, 109(4), 877-896.

Goldhaber, D. (2002, Spring). The mystery of good teaching: Surveying the evidence on student achievement and teachers' characteristics. Education Next, 2(1), 50-55. Retrieved from https://www.stcloudstate.edu/tpi/initiative/documents/preparation/The\%20Myster y\%20of\%20Good\%20Teaching.pdf

Good, T., \& Grouws, D. (1977). Teaching effects: A process-product study in fourth grade mathematics classrooms. Journal of Teacher Education, 28(3), 49-54.

Hakstian, A. R., Rogers, W. D., \& Cattell, R. B. (1982). The behavior of number-offactors rules with simulated data. Multivariate Behavioral Research, 17, 193-219.

Hamre, B., \& Pianta, R. (2001). Early teacher-child relationships and the trajectory of children's school outcomes through eighth grade. Child Development, 72(2), 625638.

Hamre, B. K., \& Pianta, R. C. (2005). Can instructional and emotional support in the first-grade classroom make a difference for children at risk of school failure? Child Development, 76(5), 949-967.

Hamre, B. K., Pianta, R. C., Downer, J. T., DeCoster, J., Mashburn, A. J., Jones, ...Hamagami, A. (2013). Teaching through interactions: Testing a developmental framework of teacher effectiveness in over 4,000 classrooms. The Elementary School Journal, 113(4), 461-487.

Hargreaves, A., \& Fullan, M. (2012). Professional capital: Transforming teaching in every school. New York: Teachers College Press. 
Hu, L., \& Bentler, P. M. (1999). Cutoff criteria for fit indexes in covariance structure analysis: Conventional criteria versus new alternatives. Structural Equation Modeling, 6, 1-55.

Hughes, J., \& Kwok, O. (2007). Influence of student-teacher and parent-teacher relationships on lower achieving readers' engagement and achievement in the primary grades. Journal of Educational Psychology, 99, 39-51.

IBM Corp. (2011). IBM SPSS Statistics for Windows, Version 20.0. Armonk, NY: IBM Corp.

Jennings, P. A., \& Greenberg, M. T. (2009). The prosocial classroom: Teacher social and emotional competence in relation to student classroom outcomes. Review of Educational Research, 79, 491-525.

Johnson, S. M., Kraft, M. A., \& Papay, J. P. (2012). How context matters in high-need schools: The effects of teachers' working conditions on their professional satisfaction and their students' achievement. Teachers College Record, 114(10), 2012.

Joreskog, K. G. (1993). Testing structural equation models. In K. A. Bollen \& J. S. Lang (Eds.), Testing structural equation models (pp. 294-316). Newbury Park, CA: Sage.

Joyce, B., \& Showers, B. (2002). Student achievement through staff development $\left(3^{\text {rd }} \mathrm{ed}.\right)$ Alexandria, VA: Association for Supervision and Curriculum Development. Kaiser, H. F. (1960). The application of electronic computers to factor analysis. Educational and Psychological Measurement, 20, 141-151. 
Kane, T. J., Kerr, K. A., \& Pianta, R. C. (2014). Designing teacher evaluation systems: New guidance from the Measures of Effective Teaching Project. San Francisco, CA: Jossey-Bass.

Kane, T. J., \& Staiger, D. O. (2012, March). Gathering feedback for teachers: Combining high quality observations with student surveys and achievement gains. Policy and practice brief prepared for the Bill \& Melinda Gates Foundation.

Kline, R. B. (2011). Principles and practice of structural equation modeling ( $3^{\text {rd }}$ ed.). New York, NY: Guilford Press.

Kounin, J., \& Doyle, P. (1975). Degree of continuity of a lesson's signal system and the task involvement of children. Journal of Educational Psychology, 67, 159-164.

Kraft, M. A., \& Papay, J. P. (2014). Can professional environments in schools promote teacher development? Explaining heterogeneity in returns to teaching experience. Educational Evaluation and Policy Analysis, 36(4), 476-500.

Le Breton, J. M., \& Senter, J. L. (2008). Answers to 20 questions about interrater reliability and interrater agreement. Organizational Research Methods, 11, 815-852.

Ladd, H. F. (2009, December). Teachers' perceptions of their working conditions: How predictive of policy-relevant outcomes? (Working Paper No. 33). Retrieved from http://www.urban.org/uploadedpdf/1001440-Teachers-perceptions.pdf

Ladd, H. F. (2011). Teachers' perceptions of their working conditions: How predictive of planned and actual teacher movement? Education Evaluation and Policy Analysis, 33(2), 235-261. doi: 10.3102/wokr0162373711398128

Leachman, M., \& Mai, C. (2014). Most states still funding schools less than before the recession. Retrieved from Center on Budget and Policy Priorities website: 


\section{http://www.cbpp.org/sites/default/files/atoms/files/10-16-14sfp.pdf}

Lerner, R. M. (1998). Theories of human development: Contemporary perspectives. In W. Damon \& R. M. Lerner (Eds.) Handbook of child psychology: Vol. 1 Theoretical models of human development $\left(5^{\text {th }}\right.$ ed., pp. 1-24). New York: Wiley.

Little, R., \& Rubin, D. (1987). Statistical analysis with missing data (2 ${ }^{\text {nd }}$ ed.). New York, NY: Wiley.

Maldonado-Carreno, C., \& Votruba-Drzal, E. (2011). Teacher-child relationships and the development of academic and behavioral skills during elementary school: A within- and between-child analysis. Child Development, 82(2), 601-616.

MacKinnon, D. P., Warsi, G., \& Dwyer, J. H. (1995). A simulation study of mediated effect measures. Multivariate Behavioral Research, 30, 1-23.

McCoach, D. B., \& Colbert, R. D. (2010). Factors underlying the collective teacher efficacy scale and their mediating role in the effect of socioeconomic status on academic achievement at the school level. Measurement and Evaluation in Counseling and Development, 43, 31-47.

Miles, M. B., Huberman, A. M., \& Saldana, J. (2014). Qualitative data analysis: A methods sourcebook ( $3^{\text {rd }}$ ed.). Washington, DC: SAGE Publications, Inc.

Moolenaar, N. M. (2012). A social network perspective on teacher collaboration in schools: Theory, methodology, and applications. American Journal of Education, 119, 7-39.

Moore, K. J., Fifield, M. B., Spira, D. A., \& Scarlato, M. (1989). Child study team decision making in special education: Improving the process. Remedial and Special Education, 10, 50-58. 
Mueller, R. O., \& Hancock, G. R. (2010). Structural equation modeling. In G. R. Hancock \& R. O. Mueller (Eds.) The reviewer's guide to quantitative methods in the social sciences (pp. 371-383). New York, NY: Routledge.

Muthen, B., \& Muthen, L. (1998-2012). Mplus user's guide (7 $7^{\text {th }}$ ed.). Los Angeles, CA: Muthen and Muthen.

Nye, B., Konstantopoulos, S., \& Hedges, L. V. (2004). How large are teacher effects? Educational Evaluation and Policy Analysis, 26(3), 237-257. doi: $10.3102 / 01623737026003237$

O’Connor, E., \& McCartney, K. (2007). Examining teacher-child relationships and achievement as part of an ecological model of development. American Educational Research Journal, 44(2), 340-369.

Odden, A. (2011). Strategic management of human capital in education: Improving instruction and student learning in schools. New York: Taylor \& Francis.

Pajares, F. (1992). Teachers' beliefs and educational research: Cleaning up a messy construct. Review of Educational Research, 62(3), 307-332.

Pajares, F. (1997). Current directions in self-efficacy research. In M. L. Maehr \& P. R. Pintrich (Eds.), Advances in motivation and achievement (pp. 1-49). Greenwich, CT: JAI Press.

Pas, E. T., \& Bradshaw, C. P. (2014). What affects teacher ratings of student behaviors? The potential influence of teachers' perceptions of the school environment and experiences. Prevention science, 15(6), 940-950. 
Paxton, C. L. C., Leis, M., \& Rimm-Kaufman, S. E. (2015). Collective efficacy and the school adult community: Results after two years of implementing Leading Together. Manuscript submitted for publication.

Perry, R. R., \& Lewis, C. C. (2008). What s successful adaptation of lesson study in the US? Journal of Educational Change, 10, 365-391.

Pianta, R. C. (1999). Enhancing relationships between children and teachers. Washington, DC: American Psychological Association.

Pianta, R. C., Hamre, B. K., \& Mintz, S. L. (2012). Classroom Assessment Scoring System (CLASS): Upper Elementary Manual. Charlottesville, VA: Teachstone.

Pianta, R. C., Hamre, B., \& Stuhlman, M. (2003). Relationships between teachers and children. In W. M. Reynolds \& G. E. Miller (Eds.), Comprehensive handbook of psychology (Vol. 7, pp. 199-234). New York: Wiley.

Ponitz, C. C., Rimm-Kaufman, S. E., Brock, L. L., \& Nathanson, L. (2009). Contributions of gender, early school adjustment, and classroom organizational climate to first grade outcomes. Elementary School Journal, 110, 143-162.

Raver, C. C., Jones, S. M., Li-Grining, C. P., Metzger, M., Smallwood, K., \& Sardin, L. (2008). Improving preschool classroom processes: Preliminary findings from a randomized trial implemented in Head Start settings. Early Childhood Research Quarterly, 23(1), 10-26.

Reyes, M. R., Brackett, M. A., Rivers, S. E., Elbertson, N. A., \& Salovey, P. (2012). The interaction effects of program training, dosage, and implementation quality on 
targeted student outcomes for the RULER approach to social and emotional learning. School Psychology Review, 41, 82-99.

Reyes, M. R., Brackett, M. A., Rivers, S. E., White, M., \& Salovey, P. (2012). Classroom emotional climate, student achievement, and academic achievement. Journal of Educational Pschology, 104(3), 700-712.

Rimm-Kaufman, S. E., Baroody, A. E., Larsen, R. A., Curby, T. W., \& Abry, T. (2015). To what extent do teacher-student interaction quality and student gender contribute to fifth graders' engagement in mathematics learning? Journal of Educational Psychology, 107, 170-186.

Rimm-Kaufman, S. E., Curby, T. W., Grimm, K. J., Nathanson, L., \& Brock, L. L. (2009). The contribution of children's self-regulation and classroom quality to children's adaptive behaviors in the kindergarten classroom. Developmental Psychology, 45, 958-972.

Rimm-Kaufman, S., \& Hamre, B. (2010). The role of psychological and developmental science efforts to improve teacher quality. Teachers College Record, 112, 29883023

Rimm-Kaufman, S. E., Larsen, R. A. A., Baroody, A. E., Curby, T. W., Ko, M., Thomas, J. B.,...DeCoster, J. (2014). Efficacy of the Responsive Classroom approach: Results from a 3-year longitudinal randomized controlled trial. American Educational Research Journal, 51, 567-603.

Rodriguez, V., \& Fitzpatrick, M. (2014). The teaching brain. New York, NY: The New Press. 
Rockoff, J. E., \& Speroni, C. (2010). Subjective and objective evaluations of teacher effectiveness. American Economic Review, 100(2), 261-266.

Rotter, J. B. (1966). Generalized expectancies for internal versus external control of reinforcement. Psychological monographs: General and applied, 80, 1-28.

Rucker, D. D., Preacher, K. J., Tormala, Z. L., \& Petty, R. E. (2011). Mediation analysis in social psychology: Current practices and new recommendations. Social and Personality Psychology Compass, 5, 359-371.

Shavelson, R. J., \& Towne, L. (Eds.) (2002). Scientific research in education. Washington, DC: National Academy Press.

Smylie, M. A., Conley, S., \& Marks, H. M. (2002). Exploring new approaches to teacher leadership for school improvement. Yearbook for the National Society for the Study of Education, 101(1), 162-188.

Split, J. L., Koomen, H. M. Y., \& Thijs, J. T. (2011). Teacher wellbeing: The importance of teacher-student relationships. Educational Psychology Review, 23, 457-477.

StataCorp. (2013). Stata Statistical Software: Release 13. College Station, TX: StataCorp LP.

Stevens, J. P. (2009). Applied multivariate statistics for the social sciences $\left(5^{\text {th }}\right.$ ed.). New York, NY: Routledge.

Tschannen-Moran, M., \& Barr, M. (2004). Fostering student learning: The relationship of collective teacher efficacy and student achievement. Leadership and Policy in Schools, 3(3), 189-209.

Tschannen-Moran, M., Woolfolk Hoy, A., \& Hoy, W. K. (1998). Teacher efficacy: Its meaning and measure. Review of Educational Research, 68(2), 202-248. 
Zuckerman, M., Hodgins, H. S., Zuckerman, A., \& Rosenthal, R. (1993). Contemporary issues in the analysis of data: A survey of 551 psychologists. Psychological Science, 4, 49-53. 


\section{APPENDICES}

\section{APPENDIX A}

Collective Teacher Efficacy Scale - Long Form (Goddard, Hoy, \& Woolfolk Hoy, 2000)

$$
\text { Item } \quad \text { GC+ GC- } \mathrm{TA}+\text { TA- }
$$

Teachers in this school have what it takes to get the children to learn.

$\mathrm{X}$

Teachers in this school are able to get through to difficult students.

Teachers here are confident they will be able to motivate their students.

Teachers in this school really believe every child can learn.

If a child doesn't learn something the first time, teachers will try another way.

Teachers here are well prepared to teach the subjects they are assigned to teach.

Teachers in this school are skilled in various methods of teaching. If a child doesn't want to learn teachers here give up.

Teachers here need more training to know how to deal with these students.

Teachers in this school think there are some students that no one can reach.

Teachers here don't have the skills needed to produce meaningful student learning.

Teachers here fail to reach some students because of poor teaching methods.

Teachers in this school do not have the skills to deal with student disciplinary problems.

These students come to school ready to learn.

Homelife provides so many advantages the students here are bound to learn.

The quality of school facilities here really facilitates the teaching and learning process.

The opportunities in this community help ensure that these students will learn.

Students here just aren't motivated to learn.

$\mathrm{X}$

$\mathrm{X}$

X

$\mathrm{X}$

$\mathrm{X}$

$\mathrm{X}$

X

$\mathrm{X}$

X

X

X

Note: Positively-worded items for group competence and task analysis are GC+ and TA+, respectively. Negatively-worded items for group competence and task analysis are GC- and TA-, respectively. 


\section{APPENDIX B}

MET Project CLASS Double Coding Reliability

\begin{tabular}{|c|c|c|c|c|}
\hline & $\begin{array}{c}\text { Percent } \\
\text { Exact }\end{array}$ & $\begin{array}{c}\text { Percent } \\
\text { Exact + } \\
\text { Adjacent }\end{array}$ & $\mathrm{ICC}$ & $\begin{array}{c}\text { Linear } \\
\text { Weighted } \\
\text { Kappa } \\
\end{array}$ \\
\hline Positive Climate & 28.2 & 74.6 & 0.42 & 0.28 \\
\hline Negative Climate & 67.5 & 95.1 & 0.49 & 0.36 \\
\hline Teacher Sensitivity & 28.7 & 72.6 & 0.33 & 0.24 \\
\hline Regard for Student Perspectives & 26.6 & 67.9 & 0.38 & 0.21 \\
\hline Behavior Management & 45.8 & 85.6 & 0.41 & 0.31 \\
\hline Productivity & 39.2 & 82.4 & 0.28 & 0.21 \\
\hline Instructional Learning Formats & 31.9 & 78.2 & 0.35 & 0.21 \\
\hline Content Understanding & 30.1 & 75.5 & 0.31 & 0.20 \\
\hline Analysis and Problem Solving & 29.6 & 71.5 & 0.26 & 0.13 \\
\hline Quality of Feedback & 28.7 & 71.9 & 0.37 & 0.24 \\
\hline Instructional Dialogue & 29.2 & 74.8 & 0.37 & 0.23 \\
\hline
\end{tabular}




\section{APPENDIX C}

\section{Full Measurement and Structural Model}

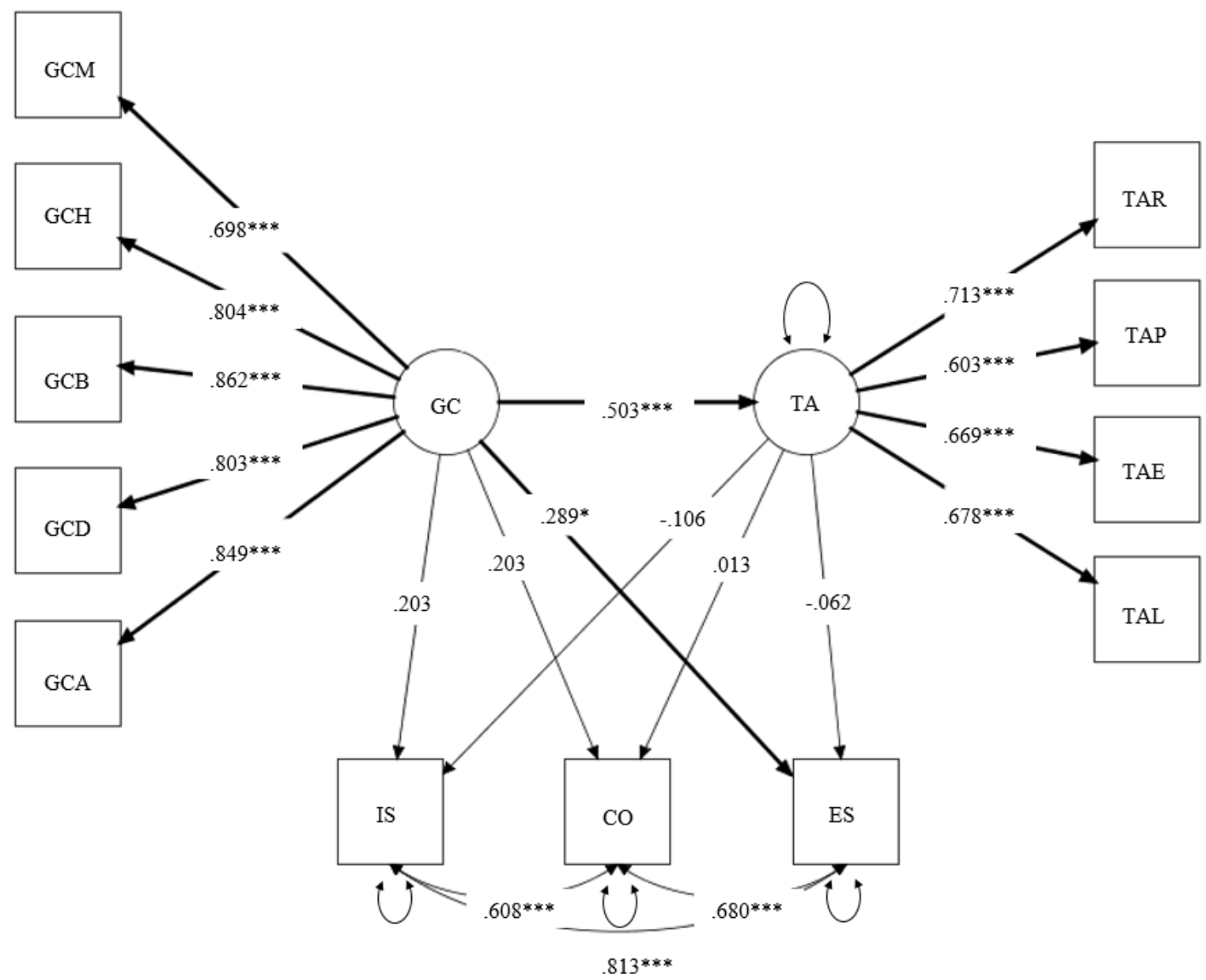

Full model with group competence (GC) directly affecting task analysis (TA) and the emotional support (ES) domain of teacher-student interaction quality. Ovals represent latent variables. Rectangles represent observed variables. Bold lines indicate significance. IS = instructional support domain; $\mathrm{CO}=$ classroom organization domain.

Note. $* p<.05, * * * p<.001$. 